\title{
ARTE RUPESTRE DEL NORTE DE GUASAPAMPA Y SERREZUELA. CONSTRUCCIÓN DEL PAISAJE Y REPRODUCCIÓN SOCIAL EN LAS SIERRAS DE CÓRDOBA (ARGENTINA)
}

\section{THE ROCK ART OF NORTHERN GUASAPAMPA AND SERREZUELA. LANDSCAPE CONSTRUCTION AND SOCIAL REPRODUCTION IN THE CÓRDOBA HILLS (ARGENTINA)}

\section{SeBAstí́N PASTOR *}

\begin{abstract}
En este artículo se presentan los resultados de investigaciones en cuatro áreas localizadas en la sección norte del valle de Guasapampa y en el cordón de Serrezuela, al occidente de la provincia de Córdoba (Argentina). El análisis se focaliza en los paneles con representaciones rupestres, específicamente sobre los motivos figurativos, que constituyen una de las principales expresiones arqueológicas del sector. Además de los aspectos formales (tipos de diseño, temas, técnicas de ejecución) se tiene en cuenta el contexto más amplio en el que se integraron las imágenes (elección de soportes, condiciones de visibilidad y otras prácticas asociadas a la producción y observación del arte rupestre). El análisis expone un panorama definido por una apreciable variabilidad local, no obstante la reducida escala geográfica del área considerada, dando cuenta de la participación diferencial de esta materialidad en el establecimiento y la delimitación de los vínculos sociales entre los grupos que la ocuparon en tiempos prehispánicos.
\end{abstract}

Palabras clave: arte rupestre, construcción del paisaje, reproducción social, variabilidad local, recursos forestales, aguadas

This paper presents the results of research conducted in four areas of the northern Guasapampa Valley and Serrezuela Hills, in the western part of Cordoba Province, Argentina. The analysis focuses on rock art panels, specifically on the figurative motifs that comprise one of the most conspicuous archaeological materialities of this sector. The evaluation considers the formal aspects of representation (design types, themes, execution techniques) as well as their context (rock support selection, visibility conditions and other practices associated with rock art production and observation). The analysis suggests considerable local variability, despite the small geographical scale of the research area, pointing to the differential participation of this materiality in establishing and defining social relations among groups inhabiting the area in pre-Hispanic times.

Key words: rock art, landscape construction, social reproduction, local variability, forest resources, water wells

\section{INTRODUCCIÓN}

En los últimos 20 años, la continuidad y la intensificación de las investigaciones en el centro de Argentina han permitido profundizar en diferentes líneas de información arqueológica e incrementar sensiblemente el conocimiento sobre los procesos prehispánicos locales, en particular en tiempos tardíos (ca. 1500/400 años AP; Berberián 1999; Laguens 1999; Pastor 2007a; Pastor \& Berberián 2007; Medina 2008; Bixio et al. 2010; Pastor et al. 2012). Un importante conjunto de expectativas deriva del estudio del arte rupestre del occidente de las sierras de Córdoba (Recalde 2006, 2009; Pastor 2010, 2012; Recalde \& Pastor 2011, 2012), en el que la ubicuidad de estas expresiones permitió establecer comparaciones con otros sectores de la región donde esta materialidad es inexistente o poco frecuente, o bien abundante pero de características disímiles, como ocurre en las sierras del norte de Córdoba (Gardner 1931; Vignati 1939; Urquiza 2011), en el sur de la sierra de Comechingones (Rocchietti 1991) y en las sierras de San Luis (Consens 1986).

Se entiende que el arte rupestre adquiere significación no solo por su forma, sino también por su emplazamiento, integrando y a la vez delimitando las prácticas sociales. En tal sentido, impone alteraciones en el paisaje que objetivan las particularidades de su

* Sebastián Pastor, Conicet, Área de Arqueología y Etnohistoria, Centro de Estudios Históricos "Prof. Carlos S. A. Segreti”, M. C. del Corro 308, (5000) Córdoba, Argentina, email: pastorvcp@yahoo.com.ar 
ocupación (Gallardo 2001), toda vez que permite -en forma consciente o inconsciente- fijar, reformular o reproducir pautas de comportamiento (Criado Boado 1999; Troncoso 2005; Aschero 2007). Por ejemplo, las condiciones de visibilidad, junto a las prácticas asociadas a su ejecución, pueden generar sentidos de igualdad y pertenencia, o de desigualdad y exclusión (Piazzini 2006), estableciendo formas de interacción entre las personas y los grupos, y entre estos y el entorno. En este trabajo se analiza y discute el papel diferencial del arte rupestre en la construcción del paisaje del occidente de Córdoba, contribuyendo a la caracterización y la comprensión del complejo mosaico cultural y de prácticas sociales que distinguieron a la región en los siglos previos a la invasión europea.

\section{PAISAIES DE GUASAPAMPA Y SERREZUELA}

El estudio se enfoca en cuatro áreas ubicadas en el valle de Guasapampa y en la sierra de Serrezuela. La primera de ellas, Totora Huasi/Agua de Ramón (TH/ $\mathrm{AR}$ ), cubre buena parte de la sección norte del valle de Guasapampa (GN) y de las lomadas que constituyen la extremidad septentrional de las sierras de Pocho, con una extensión aproximada de $150 \mathrm{~km}^{2}$ (fig. 1). El fondo de valle (500-600 msnm) está surcado por el río Guasapampa, de régimen intermitente en el extremo sur del área y únicamente activo después de las lluvias desde allí hacia el norte. A lo largo de su trayecto es acompañado por frondosos algarrobales (Prosopis sp.), que alternan con otras especies con frutos comestibles como el chañar (Geoffroea decorticans) y el mistol (Zizyphus mistol). Las lomadas hacia el occidente del fondo de valle (700-900 msnm) constituyen un paisaje agreste, topográficamente poco diferenciado y de tránsito dificultoso por una vegetación cerrada y agresivamente espinosa (aunque en los fondos de las quebradas crecen algarrobos, mistoles y otros árboles y arbustos beneficiosos). En la actualidad no hay cursos de agua activos en decenas de kilómetros de serranías, excepto tres o cuatro vertientes dispersas, permanentes aunque de modestísimo caudal. El resto se limita al agua de lluvia almacenada por algunos días o semanas en depósitos naturales ubicados en el interior de los cauces, en el fondo de quebradas (llamados "pozos" o "cajones" por los pobladores locales). En esta área se documentaron ocho sitios (sin contar aquellos que no incluyen arte rupestre), los cuales totalizan 13 paneles con representaciones grabadas y 111 motivos.
Ampiza (AM) es la segunda área en el extremo norte del valle, en su límite con el piedemonte y la llanura que desciende hacia las Salinas Grandes (fig. 1). La superficie prospectada alcanzó los $45 \mathrm{~km}^{2}$. Aquí finalizan las sierras de Pocho (reducidas a lomadas de menos de $400 \mathrm{msnm}$ ), al igual que el cauce del río Guasapampa, que desaparece tras tomar contacto con los sedimentos semiarenosos de la planicie (150-250 msnm). La distribución de los recursos hídricos muestra pocas diferencias con el área anterior, con ausencia de arroyos o manantiales permanentes y aguadas efímeras en depósitos puntuales en la quebrada principal y otras de menor jerarquía. La importancia de los recursos forestales es similar o aun mayor, en particular en la quebrada principal donde los algarrobales alcanzan un notable desarrollo. Se registraron seis sitios arqueológicos (exceptuando aquellos sin arte rupestre), conteniendo un total de nueve paneles y 106 motivos grabados.

El área de Lomas Negras (LN) cubre una pequeña cerrillada $\left(80 \mathrm{~km}^{2}\right)$ en el piedemonte occidental de la sierra de Serrezuela (fig. 1). La altura máxima del cordón principal es de $900 \mathrm{~m}$, mientras que la cerrillada varía entre 250 y $450 \mathrm{msnm}$. El sector se destaca por sus recursos forestales, pero el agua se limita a aquella almacenada en el interior de depósitos naturales ("pozos" y "cajones") o artificiales (las represas que construyen los campesinos actuales con lomadas de tierra), puesto que no existen cursos permanentes. En total se documentaron 12 sitios con arte rupestre, distribuidos en 58 paneles y 301 motivos (288 grabados, 11 pintados y dos donde ambas técnicas de ejecución se combinan).

La cuarta área es Virgen de la Peña (VP), extendida por $25 \mathrm{~km}^{2}$ en el piedemonte oriental de Serrezuela ( $c a$. 300-400 msnm; fig. 1). Como ocurre en el piedemonte occidental, no existen cursos de agua permanentes, pero sí algunos pozos importantes que en la actualidad mantienen el líquido durante todo el año. Se registraron seis sitios que contienen nueve paneles con arte rupestre y 130 motivos. Cinco de ellos muestran representaciones grabadas mientras que el sexto y más destacado (Pozo de la Tosca 2) incluye dos motivos grabados y 115 pintados.

Para finalizar, nos referiremos brevemente a la sección sur del valle de Guasapampa (GS), localizada hacia el sur del área TH/AR (fig. 1) y reconocida por contener la mayor concentración de sitios con arte rupestre del noroccidente cordobés. En efecto, en una pequeña área que no sobrepasa los $20 \mathrm{~km}^{2}$ se documentaron 35 sitios que conservan 64 paneles y 650 motivos. ${ }^{1}$ La información obtenida (Recalde 2009; Recalde \& Pastor 2012) será considerada en este trabajo por su inmediata proximidad geográfica y porque sus expresiones rupestres se relacionan con (y en parte dan cuenta de) 


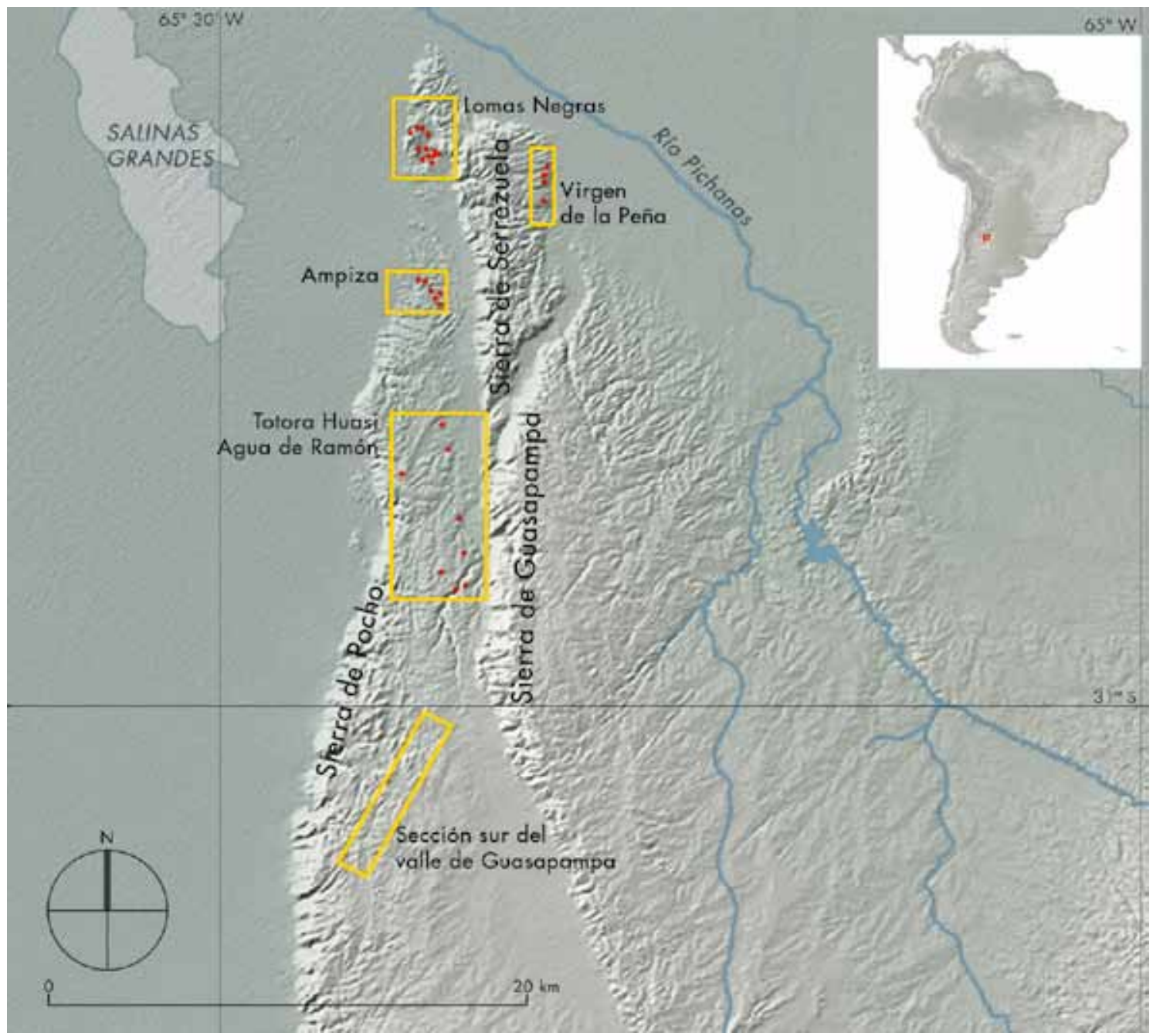

Figura 1. Localización de las áreas investigadas.

Figure 1. Location of the areas of study.

los procesos e interacciones sociales investigados. Las características fisiográficas de GS son muy similares a GN, con un clima cálido, acentuada escasez hídrica con ausencia de cursos permanentes (excepto el río Guasapampa en sus tramos iniciales, donde discurre en forma intermitente) y abundancia y variedad de recursos forestales chaqueños.

\section{TIPOS DE MOTIVO, CÁNONES Y PATRONES CONSTRUCTIVOS}

Los tipos de motivo son divididos en figurativos y no figurativos, según la posibilidad de asignarlos o no a un referente objetivo. En el segundo caso no se niega su vínculo con algún referente del mundo material (persona, animal, vegetal u objeto), solo que dicha posibilidad no puede ser establecida con certeza.

Entre los motivos figurativos predominan ampliamente los camélidos, los únicos registrados en todas las áreas aunque en proporciones variables (Tabla 1). Se observan distintas formas de construir la figura de estos animales, lo cual justifica la distinción de cánones y patrones constructivos (sensu Aschero 1996). Las principales características formales de estos diseños y las tendencias de su distribución espacial fueron analizadas en otra oportunidad (Recalde \& Pastor 2011). En esta ocasión nos limitaremos únicamente a repasar los rasgos distintivos de los cánones más conspicuos en las áreas investigadas. El más frecuente es el canon A, definido inicialmente para GS (Recalde 2009) y presente en todas las áreas investigadas. Se muestra de perfil no 
Tabla 1. Tipos de motivo.

Table 1. Types of motifs.

\begin{tabular}{|c|c|c|c|c|c|c|c|c|}
\hline \multirow{2}{*}{$\begin{array}{l}\text { Tipo de motivo } \\
\text { Camélido }\end{array}$} & \multicolumn{2}{|c|}{$\begin{array}{l}\text { A. de Ramón / } \\
\text { Totora Huasi }\end{array}$} & \multicolumn{2}{|c|}{ Ampiza } & \multicolumn{2}{|c|}{ Lomas Negras } & \multicolumn{2}{|c|}{ Virgen de la Peña } \\
\hline & 2 & $1,8 \%$ & 44 & $41,51 \%$ & 112 & $37,21 \%$ & 30 & $23,08 \%$ \\
\hline Camélido bicápite & - & - & - & - & 1 & $0,33 \%$ & 1 & $0,77 \%$ \\
\hline Cabeza de camélido & - & - & - & - & 1 & $0,33 \%$ & - & - \\
\hline Cánido & - & - & 1 & $0,94 \%$ & 1 & $0,33 \%$ & - & - \\
\hline Felino & - & - & - & - & 1 & $0,33 \%$ & 2 & $1,54 \%$ \\
\hline Pisada de felino & 1 & $0,9 \%$ & - & - & 8 & $2,66 \%$ & - & - \\
\hline Lagarto & 1 & $0,9 \%$ & - & - & 1 & $0,33 \%$ & - & - \\
\hline Rheido & - & - & - & - & - & - & 1 & $0,77 \%$ \\
\hline Pisada de ave & 1 & $0,9 \%$ & - & - & 1 & $0,33 \%$ & 1 & $0,77 \%$ \\
\hline Équido & - & - & - & - & 1 & $0,33 \%$ & - & - \\
\hline Cuero abierto & - & - & - & - & - & - & 1 & $0,77 \%$ \\
\hline Zoomorfo indeterminado & - & - & - & - & - & - & 7 & $5,38 \%$ \\
\hline Antropomorfo A & 7 & $6,31 \%$ & 4 & $3,77 \%$ & 3 & $1,00 \%$ & 1 & $0,77 \%$ \\
\hline $\begin{array}{l}\text { Antropomorfos A3-B-C (con } \\
\text { aditamentos) }\end{array}$ & 25 & $22,52 \%$ & 16 & $15,09 \%$ & 36 & $11,96 \%$ & - & - \\
\hline $\begin{array}{l}\text { Pisada humana } \\
\text { (antropomorfo D) }\end{array}$ & - & - & - & - & 3 & $1,00 \%$ & - & - \\
\hline No figurativo & 74 & $66,67 \%$ & 41 & $38,68 \%$ & 132 & $43,85 \%$ & 86 & $66,15 \%$ \\
\hline Total & 111 & $100 \%$ & 106 & $100 \%$ & 301 & $100 \%$ & 130 & $100 \%$ \\
\hline
\end{tabular}

absoluto (con indicación de dos orejas y cuatro patas), partiendo de un cuerpo de forma elíptica al que se agregan el cuello, la cabeza, la cola y las extremidades. Sus proporciones guardan relación con el referente objetivo. Se diferencian patrones constructivos a partir de variaciones en el grosor del cuello y cuerpo, el número de extremidades representadas, su forma de inserción en el cuerpo y otros detalles (figs. 2-6).

Otra modalidad corresponde al canon $C$, que se define por un cuerpo de contorno rectangular donde se insertan las patas y el cuello, que guardan relación directa con el referente formal (Recalde 2009). En GS se combinan dos planos, con el cuerpo y las extremidades de perfil absoluto (solo se indican dos patas) y la cabeza de tres cuartos de perfil, puesto que se señalan las dos orejas. En GN y Serrezuela diferenciamos patrones constructivos donde varían las combinaciones de planos y las proporciones entre las partes del animal (figs. 2 y 3 ).

Algunos diseños se limitan a sitios puntuales en Serrezuela y faltan por completo en el valle de Guasapampa (GN y GS). El canon F, sumamente esquemático, fue registrado en dos sitios cercanos del área LN. La cola, el cuerpo, el cuello y la cabeza se

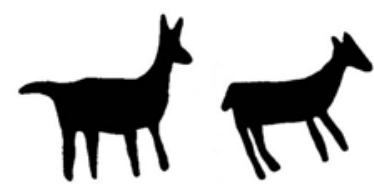

Patrón Al

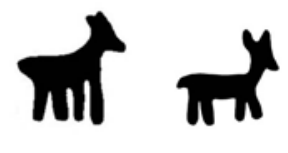

Patrón A2

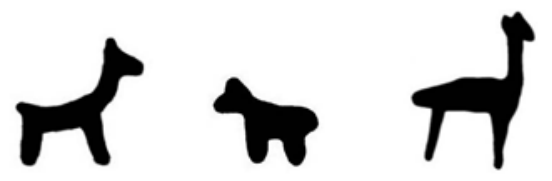

Patrones constructivos del canon C

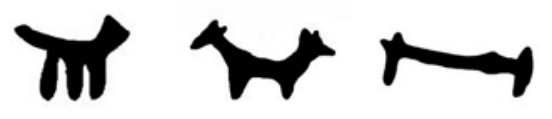

Cánones F, G y H

Figura 2. Algunos cánones y patrones constructivos de las figuras de camélidos.

Figure 2. Some canons and constructive patterns of the camelid figures. 


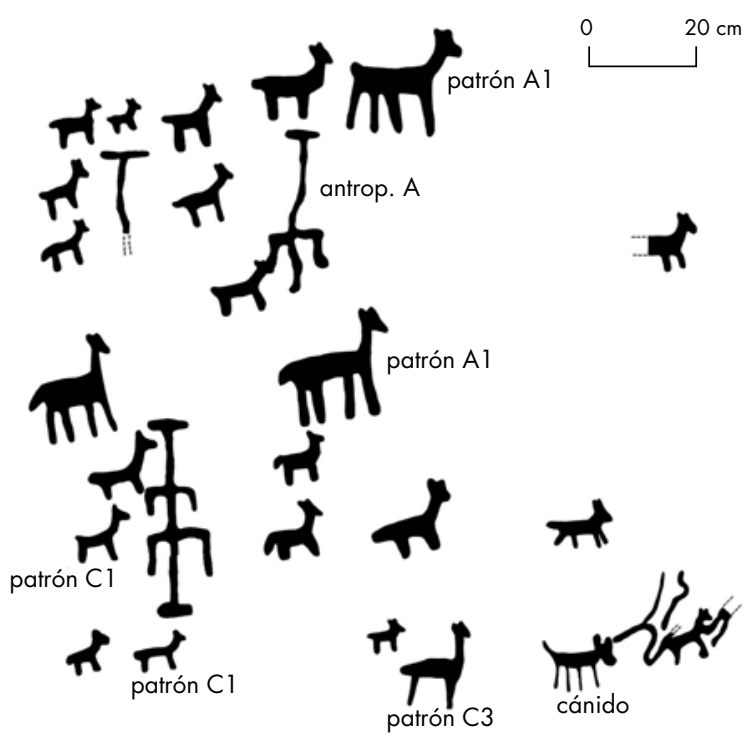

Figura 3. Representaciones grabadas en el sitio Ampiza 2. Figure 3. Engraved representations from the Ampiza 2 site.

componen por un único trazo en forma de $\mathrm{U}$ y solo se indican tres patas (fig. 2). El canon $G$ incluye a un motivo presente en la misma localidad de LN (Cajones del Igno) y a un segundo en el área VP. Se trata de un diseño esquemático, de perfil absoluto en el caso del cuerpo, con indicación de dos orejas y dos extremidades en el primer caso, y de dos orejas y cuatro extremidades en el segundo. La particularidad viene dada porque, en lugar de colas, se ejecutaron cuellos y cabezas de características similares a las primeras (bicápites; figs. 2 y 7). Por último, el canon $\mathrm{H}$ se limita a cuatro motivos estrechamente relacionados entre sí en el sitio Pozo de la Tosca 2 (área VP). Se trata de un diseño de máximo esquematismo, con indicaciones limitadas a un cuerpo de forma lineal, cola, una pata trasera, cabeza y una o dos orejas (figs. 2 y 8 ).
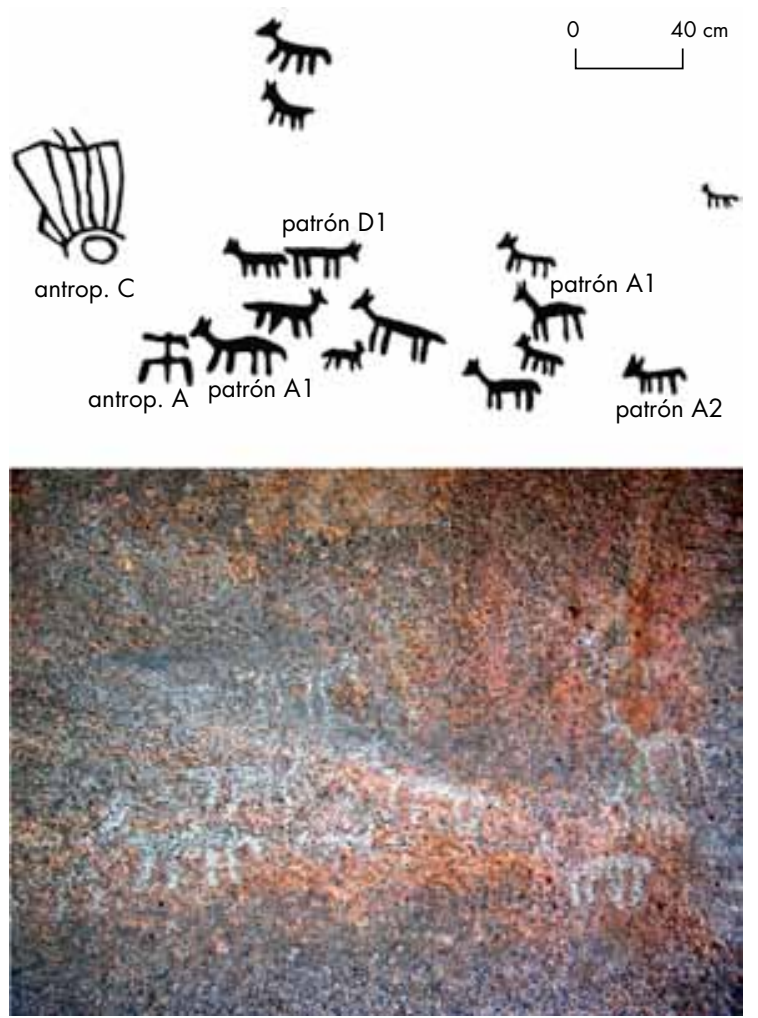

Figura 4. Panel $\mathrm{N}^{\mathrm{o}} 2$ (y detalle) del sitio Cajones del Igno 3 (LN). Figure 4. Panel $N^{\circ} 2$ (and detail) from Cajones del Igno 3 site (LN).

Sin contar a los camélidos, los restantes motivos zoomorfos son menos frecuentes y se restringen a figuras puntuales o poco numerosas, localizadas en determinadas áreas o en sitios específicos (Tabla 1). Un motivo documentado en el área AM y otro en LN fueron asignados a cánidos, por sus similitudes con dichos referentes ( $p$. ej., zorros [Licalopex sp.]). Presentan cuerpos delgados y rectangulares, patas alargadas, orejas y cola destacadas (fig. 3). Por su parte, una figura del sitio Cajones del Igno 1 (LN, fig. 9) y dos de Pozo de la Tosca 2 (VP, fig. 8)

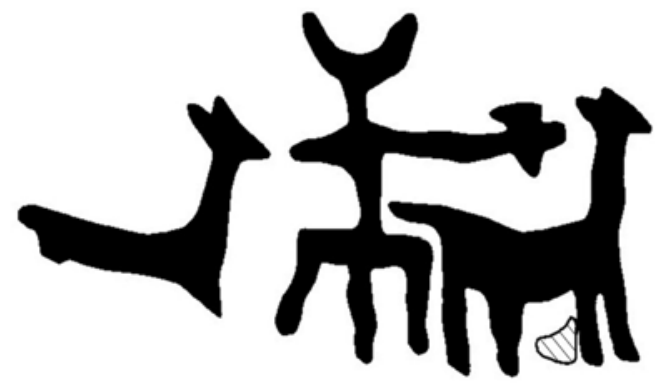

0 $20 \mathrm{~cm}$

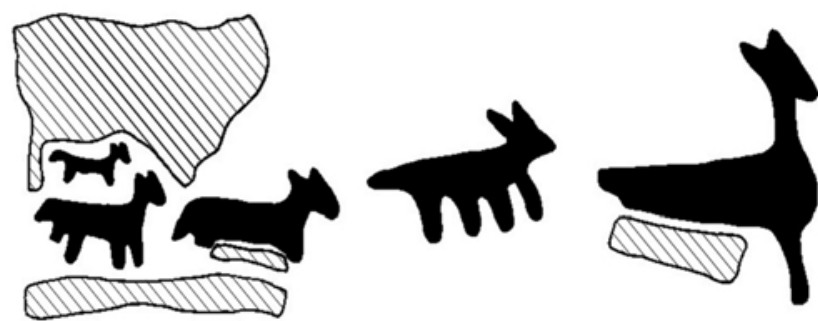

Poco visible

Figura 5. Grabados en el panel $\mathrm{N}^{\circ} 4$ del sitio Sacha Cabra 2 (LN).

Figure 5. Engravings on panel $N^{\circ} 4$ of the Sacha Cabra 2 site (LN). 

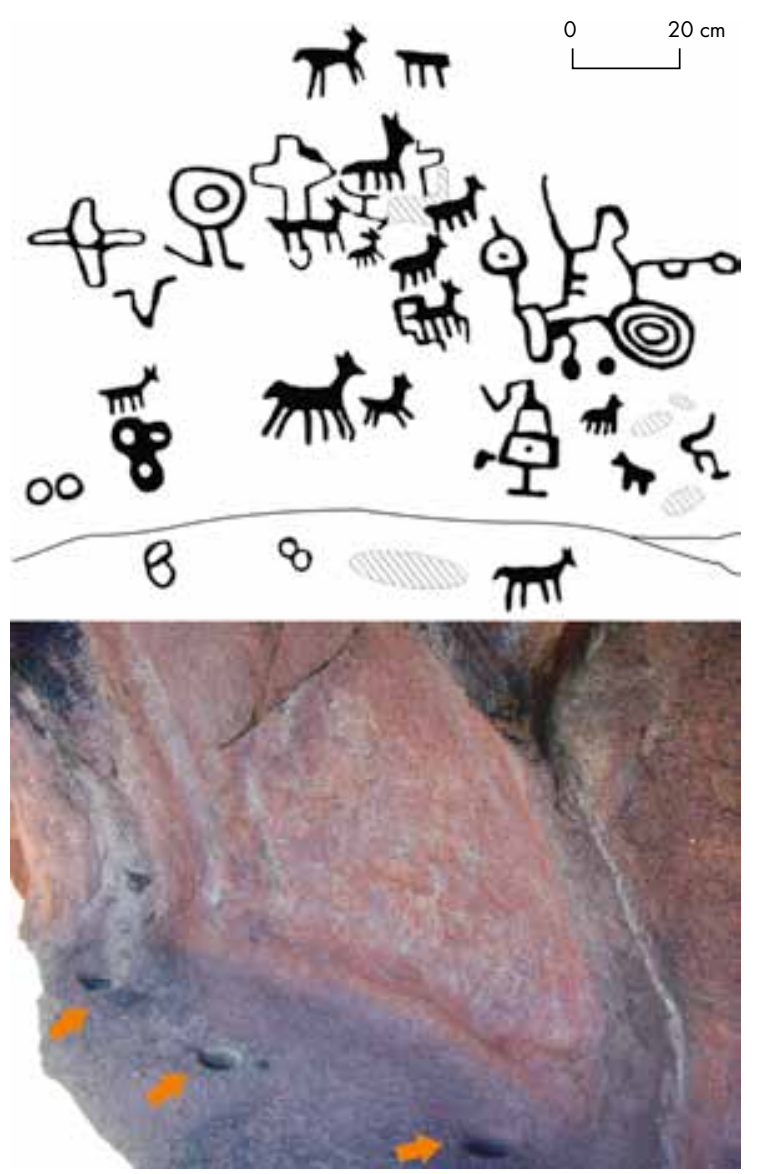

Figura 6. Articulación directa entre la ejecución/observación de las imágenes y el procesamiento de alimentos en útiles de molienda. Sitio Cerco Quemado (LN).

Figure 6. Direct association between execution/observation of the images and food processing with grinding tools. Cerco Quemado site $(L N)$.

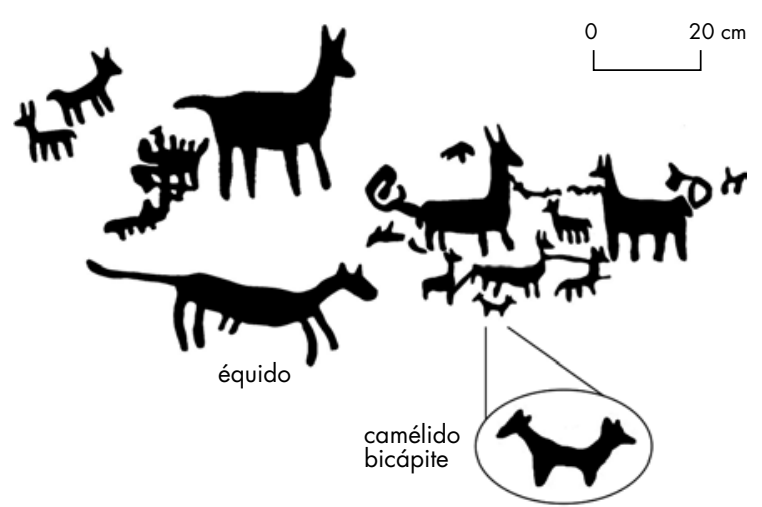

Figura 7. Grabados del sitio Cajones del Igno 4, panel $\mathrm{N}^{\circ} 1$ (LN). Figure 7. Engravings from panel $N^{o} 1$ of the Cajones del Igno 4 site $(L N)$. fueron referidas a felinos. Se diferencian por la forma de la cabeza, las orejas y/o por la cola larga y parada.

En dos sitios de LN y en uno de TH/AR se observaron pisadas de felino. Se trata de representaciones comunes en diversas regiones del país (Cuyo, Patagonia, Noroeste), pero fuera de estos ejemplos, están ausentes en el resto del noroccidente de Córdoba y son muy poco frecuentes en el centro de Argentina (Raggio 1979; Schobinger \& Gradin 1985; Consens 1986; Rocchietti 1991; Falchi et al. 2011; Re et al. 2011). Su diseño parte de un círculo central de mayor tamaño, en torno al cual se disponen círculos menores indicando los dedos (fig. 10).

Dos tipos de motivos zoomorfos son exclusivos del sitio Pozo de la Tosca 2 (VP): un ñandú (Rhea sp.) y una figura interpretada como un cuero abierto (figs. 8 y 11). ${ }^{2}$ En GS las figuras de rheidos son frecuentes y corresponden a un único canon, el cual "parte de una definición redondeada o elíptica del cuerpo, al cual se agregan un cuello largo, dos alas y dos extremidades inferiores que pueden o no culminar en las garras tridígitas del ave" (Recalde 2009: 46). Dicho canon incluye variantes definidas por una resolución más esquemática, entre las cuales se encuadra el motivo de VP.

En GS se documentaron representaciones de teíidos (p. ej., Tupinambis sp.) de un canon de diseño básico y dos variantes diferenciadas por su grado de esquematismo. "En el primero se respetan las proporciones y los rasgos constitutivos, es decir una cabeza triangular, las cuatro extremidades cortas y extendidas, que pueden o no tener la indicación de los dedos, y la larga cola que se afina paulatinamente" (Recalde 2009: 46). El segundo patrón es una simplificación del primero y se distingue por presentar una cabeza redonda y el cuerpo y extremidades definidos por líneas rectas. En nuestra área solo observamos dos representaciones de teíidos. Una de ellas se ubica en TH/AR y pertenece al segundo patrón definido para el sector contiguo de GS. La segunda se encuentra en LN y su deficiente conservación impide apreciar algunos detalles, aunque se trata de una resolución con un esquematismo intermedio entre los dos patrones definidos para GS (fig. 9).

En el sitio Cajones del Igno 4 (área LN) se conserva un panel que integra figuras de camélidos (algunos atados por el cuello con sogas y uno bicápite) y motivos no figurativos. La pátina más reciente indica que a este conjunto original se le agregó la imagen de un équido. No obstante se trata de una representación de apariencia antigua, ajustada a los cánones indígenas de diseño (fig. 7). En GS se documentaron representaciones de équidos en dos sitios de la subárea de Charquina (Recalde 2012), que sugieren cambios y continuidades en torno a la ejecución y la significación del arte rupestre 


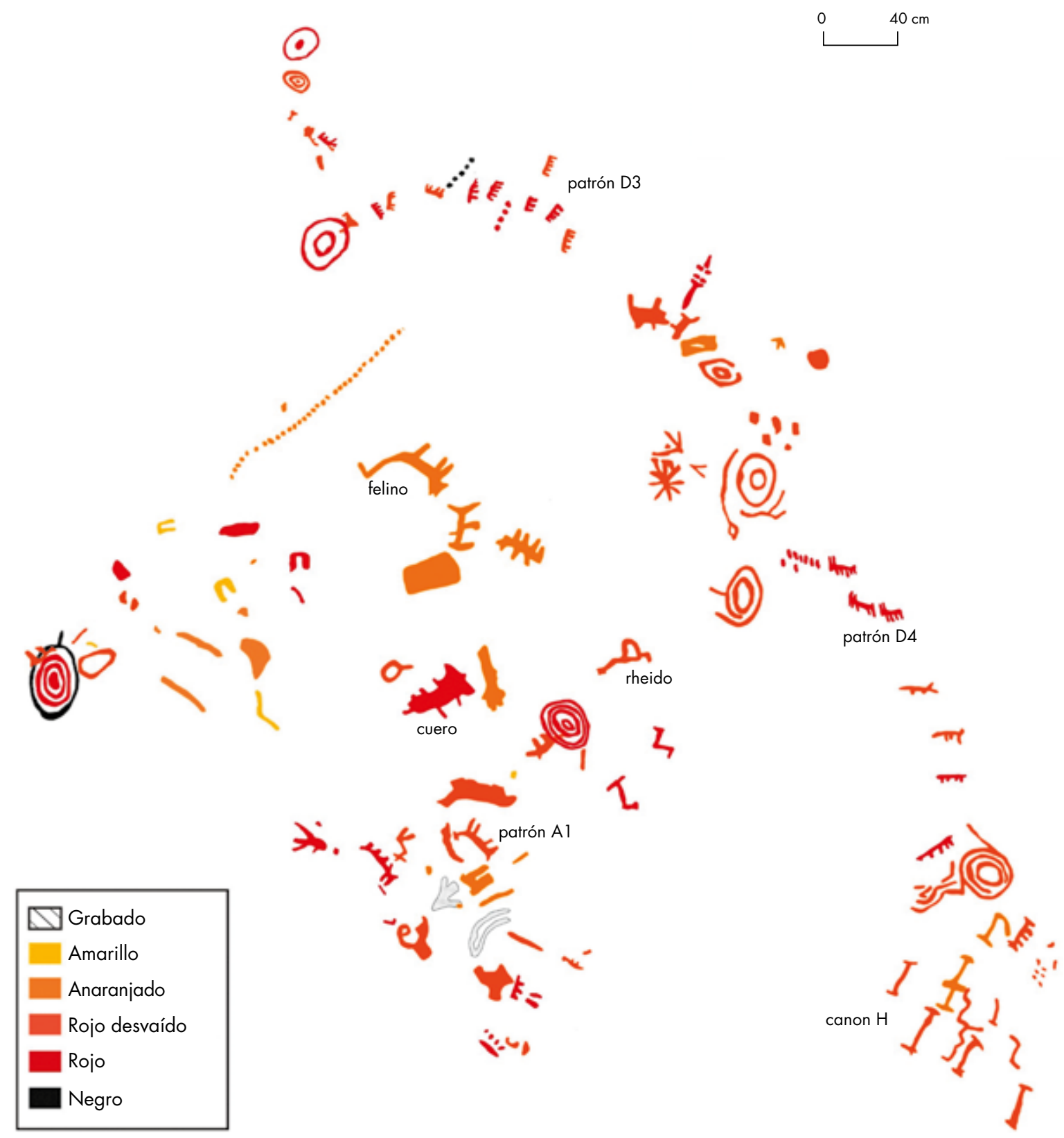

Figura 8. Panel del sitio Pozo de la Tosca 2 (VP).

Figure 8. Panel of the Pozo de la Tosca 2 site (VP).

en tiempos coloniales tempranos (siglo XVI y principios del XVII). Los restantes motivos zoomorfos comprenden pisadas de ave (en sitios puntuales en tres de las cuatro áreas) y una representación de un camélido limitada a la cabeza del animal (en el área LN).

Las figuras antropomorfas también muestran una considerable variabilidad en sus diseños, lo cual ha justificado la definición de cánones y patrones constructivos (Recalde \& Pastor 2012). El canon A, casi exclusivo en GS, está presente en todas las áreas prospectadas en GN y Serrezuela. Se caracteriza por una resolución lineal, donde "los brazos apenas se destacan y [...] se despliegan conformando una 'T' o una 'M' con el torso [...] no está indicada la cabeza [...] y solo aparece como una prolongación del tronco o como un pequeño trazo perpendicular respecto al cuerpo" (Recalde 2009: 48). Una característica común es la indicación del sexo (figs. 3, 4 y 9). 

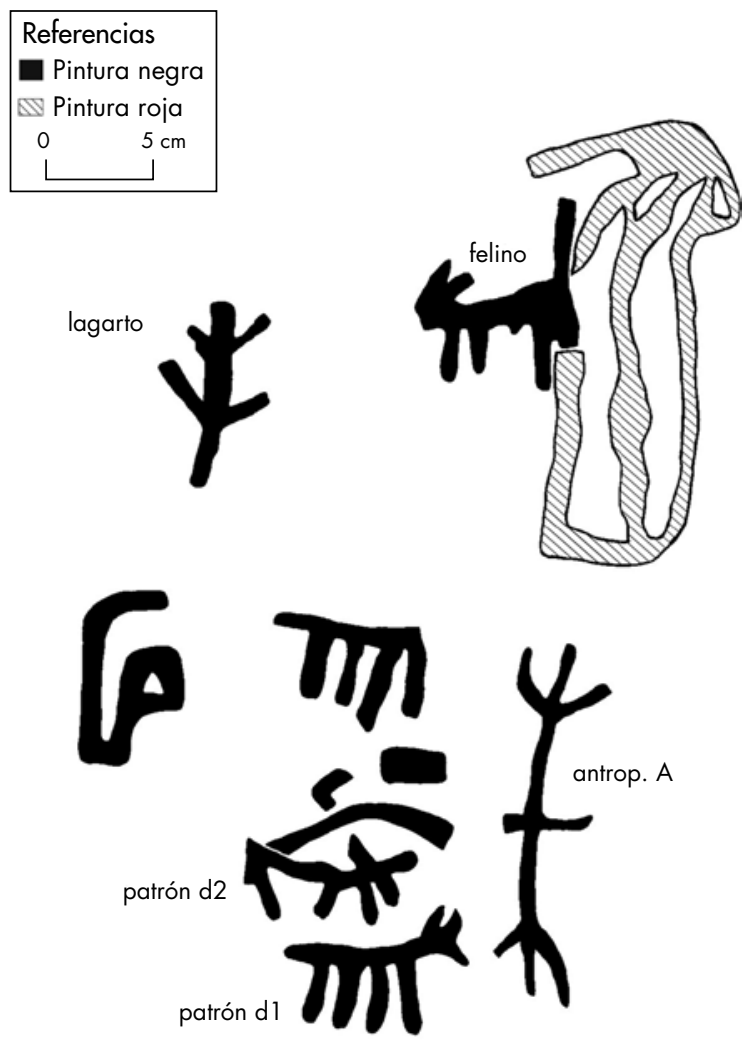

Figura 9. Representaciones pintadas en el sitio Cajones del Igno 1, panel $\mathrm{N}^{\circ} 4(\mathrm{LN})$.

Figure 9. Painted representations from panel $N^{\circ} 4$ of the Cajones del Igno 1 site $(L N)$.

Las representaciones asignadas al canon $\mathrm{B}$, así como las del patrón constructivo A3, comprenden figuras humanas de cuerpo completo, en tanto que las del canon C se limitan a la representación de la cabeza. En todos los casos destaca la indicación de aditamentos como tocados cefálicos, máscaras, vestimentas y objetos portados en las manos. Los diversos patrones constructivos son diferenciados según el mayor o menor grado de detalle y esquematismo (figs. 4, 5, 10, 12 y 13). Además de estar casi ausentes en GS, estos antropomorfos con aditamentos son inexistentes en VP. Por el contrario, se presentan en frecuencias relativamente bajas pero constantes en TH/AR, AM y LN (Tabla 1).

Finalmente, el canon $\mathrm{D}$ se restringe a tres pisadas humanas documentadas en un sitio del área LN (fig. 10). Las representaciones de huellas de pies humanos son frecuentes en sitios de la Patagonia (con el llamado "estilo de pisadas"; Menghin 1957), así como en Cuyo y el Noroeste Argentino (Schobinger \& Gradin 1985; Falchi et al. 2011; Re et al. 2011). Sin embargo, en las sierras de Córdoba solo fueron registradas en un sitio del valle de Punilla (San Buenaventura), donde se asocian

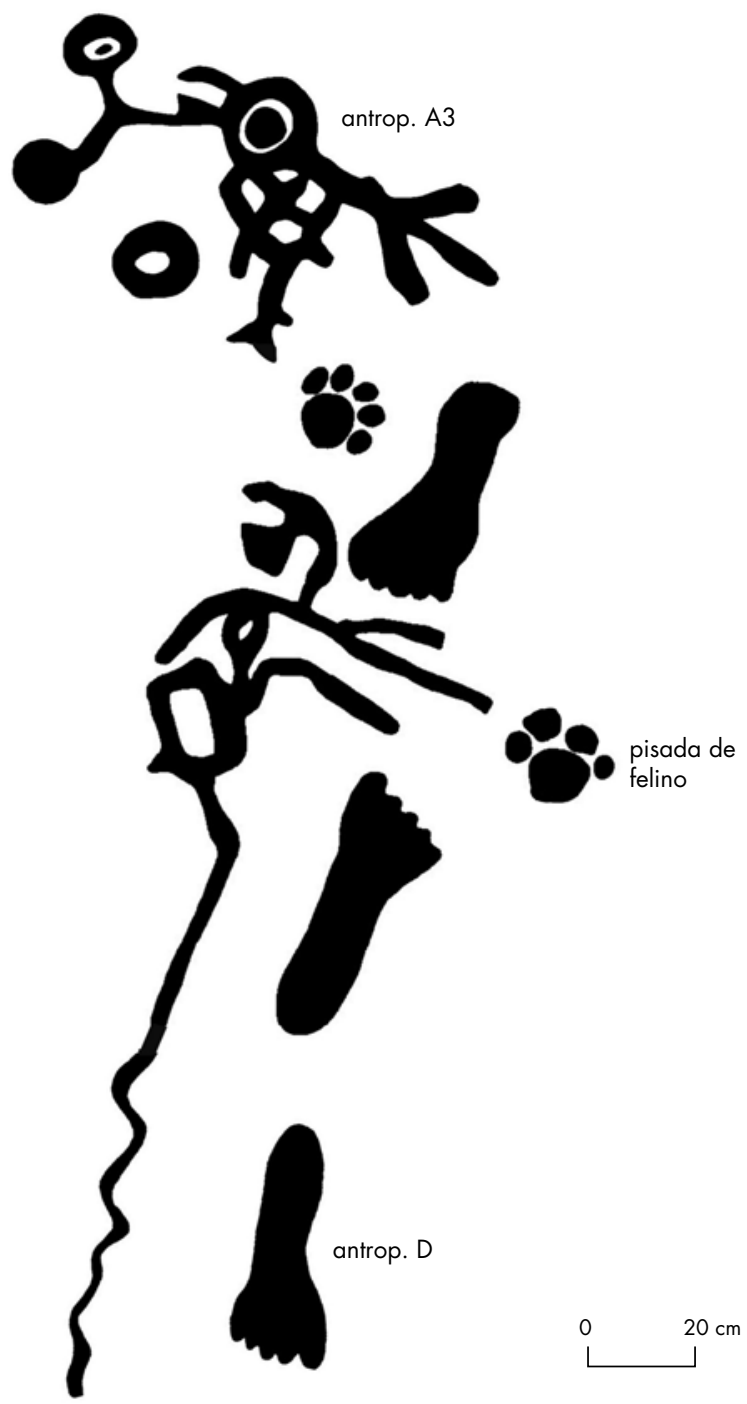

Figura 10. Grabados en el sitio Cajones del Igno 1, panel No 8 (LN). Figure 10. Engravings from panel $N^{\circ} 8$ of the Cajones del Igno 1 site $(L N)$.

a motivos no figurativos y a huellas de felinos y aves (Raggio 1979).

Los motivos no figurativos son altamente variables y se presentan en frecuencias significativas, con un mínimo del 39\% en el área AM y un máximo del 66\% en TH/AR y VP (Tabla 1). Su análisis merece un estudio detallado que, sin embargo, excede los límites de este trabajo. Se registraron diversas figuras simples (lineales, circulares, cuadrangulares) así como motivos geométricos más complejos (figs. 6-10 y 12). En el sitio El Cajón (LN) se conservan 12 paneles con numerosos hoyuelos pulidos pequeños $(3 \mathrm{o} 4 \mathrm{~cm}$ de diámetro por $1 \mathrm{~cm}$ de profundidad), distribuidos en forma aleatoria excepto en un panel donde aparecen en sucesión lineal 


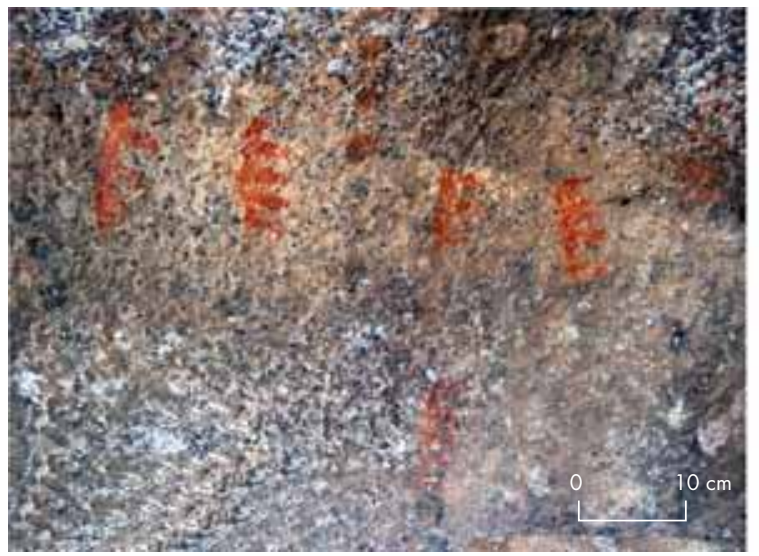

Figura 11. Detalles del panel del sitio Pozo de la Tosca 2 (VP). Figure 11. Panel detail from the Pozo de la Tosca 2 site (VP).
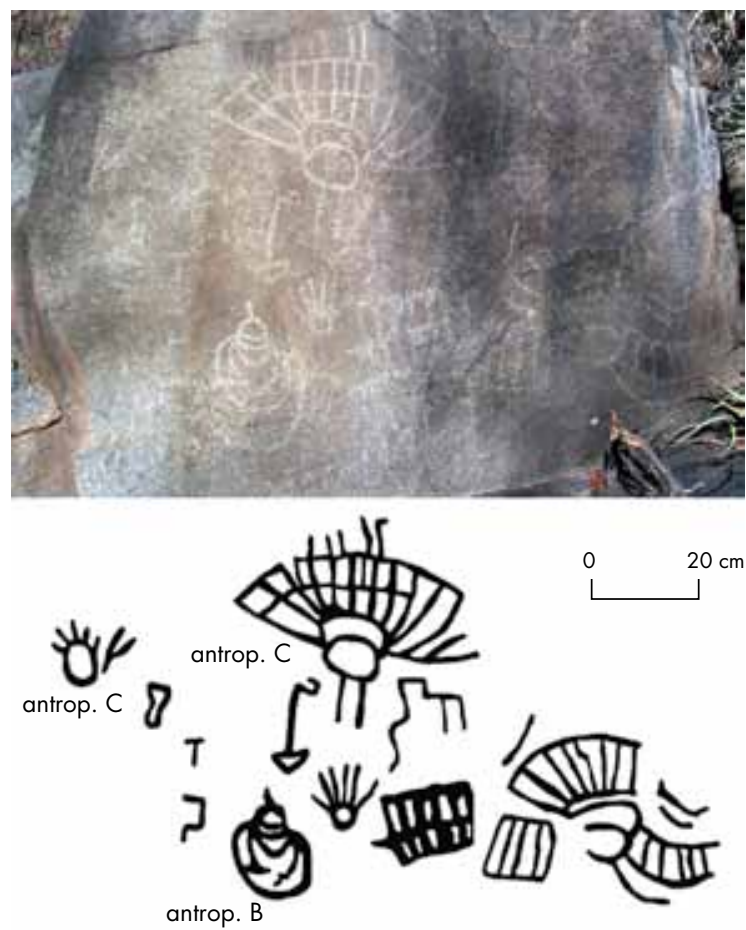

Figura 12. Grabados en el sitio Quebrada de los Zorros (TH/AR) Figure 12. Engravings from the Quebrada de los Zorros site (TH/AR).

(Pastor 2010). Se registraron representaciones similares en otros sitios del noroccidente cordobés (áreas de LN, AM, Piedrita Blanca y Ciénaga del Coro), así como en el resto de la región (valles de Punilla y Traslasierra, pampa de Achala, sierra de Comechingones), pero no en forma concentrada como ocurre en El Cajón, sino como paneles puntuales (Pastor 2007a; Rocchietti 2009; Recalde com. pers. 2010).

Como síntesis de la información cuantitativa sobre los diferentes tipos de motivo (Tabla 1) y sobre los diseños, se adelantan los siguientes resultados:
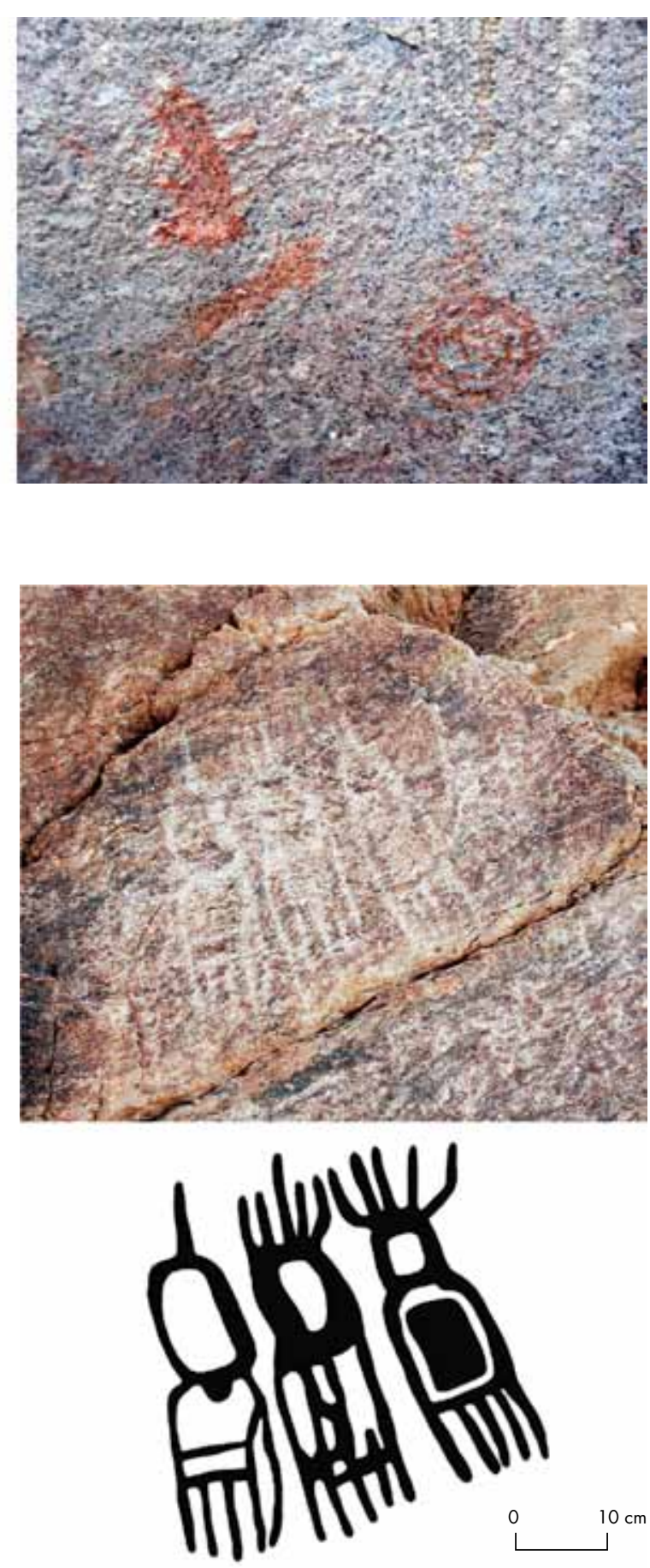

Figura 13. Antropomorfos del canon B en el sitio Río Guasapampa 2 (AM).

Figure 13. Anthropomorphic figures from Canon B of the Rio Guasapampa 2 site (AM).

- Entre los motivos figurativos destaca una alta representación de camélidos, con porcentajes elevados en todas las áreas (no menores al 25\% del total), 
excepto en $\mathrm{TH} / \mathrm{AR}$ donde solo se registraron dos figuras ( $1,8 \%$ del total).

- Con respecto a los cánones y patrones constructivos: 1) los camélidos del canon $\mathrm{A}$, y en particular los del patrón A1 y A2, son los más frecuentes y comunes a las distintas áreas investigadas; 2) las imágenes construidas a partir de los restantes patrones del canon A ocurren con escasa frecuencia o en ocasiones únicas, como sucede con los cánones B (sensu Recalde \& Pastor 2011), F, G y H, y 3) el canon C, con sus diferentes patrones constructivos, se presenta en menor proporción que el A, pero fue registrado en todas las áreas y en varios sitios $(n=7)$, excepto en $\mathrm{TH} / \mathrm{AR}$.

- Los restantes motivos zoomorfos se presentan en bajas proporciones o en una sola ocasión: cánidos (dos motivos en dos sitios), felinos (tres motivos en dos sitios), rheidos (motivo único), teíidos (dos motivos en dos sitios), équidos (motivo único), cuero abierto (motivo único, aunque ver nota 1 ) y pisadas de aves (tres motivos en tres sitios).

- Las pisadas de felino, aunque escasas, tienen una representación mayor que los anteriores. Se documentaron siete motivos en dos sitios cercanos del área LN y uno en un sitio de TH/AR.

- Los antropomorfos del canon A están presentes en todas las áreas (incluyendo GS), aunque en bajas proporciones. En el otro extremo, el canon D (pisadas) se limita a un único panel en LN.

- Los antropomorfos de los cánones B y C (así como los del patrón A3), definidos por la indicación de aditamentos, están presentes en todas las áreas con porcentajes bajos pero constantes (entre 8\% y 15\% del total), excepto en VP donde son inexistentes (al igual que en GS, con solo tres excepciones entre varios cientos de motivos).

- Los motivos no figurativos son mayoritarios en todas las áreas, donde comprenden cuanto menos la mitad de las representaciones (excepto en AM donde alcanzan un $37,5 \%$ del total, siendo superados por los camélidos).

\section{TEMAS O ASOCIACIONES DE MOTIVOS}

En la Tabla 2 se resume la información sobre los temas identificados en cada área. ${ }^{3}$ Como se puede apreciar, las figuras de camélidos son significativas en la conformación de nueve de los 19 temas, ya sea por su predominio en el total de representaciones o por el destaque de algunas figuras en particular. Algunos de estos temas son relativamente comunes, pues han sido registrados en diferentes áreas y en más de una oportunidad (p. ej., la asociación de camélidos entre sí, de camélidos y no figurativos, o de camélidos y antropomorfos A). Otros son únicos ya que integran una mayor variedad de motivos, como zoomorfos de otras especies y antropomorfos. En gran medida, son estos motivos más puntuales los que otorgan singularidad a muchos paneles, contribuyendo así a la especificación de los lugares que los contienen.

También son nueve los temas definidos a partir de los antropomorfos con aditamentos (cánones B, C y patrón constructivo A3), ya sea por su número o la relevancia de algunas figuras particulares, dada por su tamaño y/o posición. Estos antropomorfos se presentan solos o acompañados por motivos no figurativos y muy escasos zoomorfos (camélidos, un lagarto y pisadas de felino). Los temas con antropomorfos con aditamentos no son comunes a todas las áreas, pues faltan por completo en VP y casi por completo en GS (excepto el sitio Barranca Honda 2).

El tema restante agrupa a los paneles con motivos no figurativos. Su tratamiento conjunto responde a un criterio arbitrario para esta etapa de la investigación. De hecho, se reconoce en este conjunto de expresiones la existencia de patrones, similitudes y diferencias, que ameritan un examen detallado que aún se encuentra en curso y por ello no es presentado en esta oportunidad.

El análisis de las diferencias tonales, grados de pátina y superposiciones aportó elementos necesarios para entender la formación de los conjuntos, definir o deslindar asociaciones temáticas, evaluar cambios y continuidades en el uso de los soportes y, comprendiendo al entorno circundante, en la construcción social del paisaje. Se efectuaron dos tipos de observaciones de interés. En numerosas ocasiones se confirmó el carácter "aditivo" del arte rupestre (Aschero 1997), lo cual sugiere en cada caso particular, determinadas continuidades y cambios en torno a las prácticas ligadas a su producción y significación en el pasado. En la mayoría de los casos las figuras fueron agregadas a los paneles sin alterar su temática (por ejemplo, asociaciones de camélidos formadas por la agregación sucesiva de las figuras individuales). En dos oportunidades (en un sitio de LN y en otro de AM) se quebró la concepción temática de las asociaciones originales, puesto que los motivos agregados son antropomorfos B y C que se superponen a camélidos, junto a rayados intencionales de vastos sectores de la superficie rocosa, realizados con el evidente propósito de destruir o invisibilizar a las imágenes pre-existentes (Pastor 2012).

La Tabla 3 reúne algunos datos sobre las asociaciones temáticas que comentaremos brevemente. En la primera 
Tabla 2. Temas o asociaciones de motivos.

Table 2. Themes or motifs associations.

\begin{tabular}{|c|c|c|c|c|}
\hline Tema & $\begin{array}{l}\text { Totora Huasi / A. } \\
\text { de Ramón }\end{array}$ & Ampiza & Lomas Negras & $\begin{array}{l}\text { Virgen } \\
\text { de la Peña }\end{array}$ \\
\hline Antropomorfo A, camélidos & - & 1 & 3 & 1 \\
\hline $\begin{array}{l}\text { Antropomorfos A, camélidos, cánido y no } \\
\text { figurativo }\end{array}$ & - & 1 & - & - \\
\hline $\begin{array}{l}\text { Antropomorfo A, camélidos, felino, lagarto y no } \\
\text { figurativos }\end{array}$ & - & - & 1 & - \\
\hline $\begin{array}{l}\text { Antropomorfos A, B y C, camélido, lagarto y no } \\
\text { figurativos }\end{array}$ & 1 & - & - & - \\
\hline $\begin{array}{l}\text { Antropomorfo A3, pisadas humanas } \\
\text { (antropomorfo D) y de felino, no figurativos }\end{array}$ & - & - & 1 & - \\
\hline $\begin{array}{l}\text { Antropomorfos A3, B y C, camélidos, pisada de } \\
\text { ave y no figurativos }\end{array}$ & - & - & 1 & - \\
\hline Antropomorfos B alineados & - & 1 & - & - \\
\hline Antropomorfo C & 2 & - & 4 & - \\
\hline Antropomorfo C y no figurativos & 1 & 1 & 2 & - \\
\hline Antropomorfos C y B, no figurativos & 2 & - & - & - \\
\hline $\begin{array}{l}\text { Antropomorfos C, pisadas de felino y no } \\
\text { figurativos }\end{array}$ & 1 & - & 2 & - \\
\hline Antropomorfos C, pisada de ave y no figurativo & 1 & - & - & - \\
\hline Camélido aislado & 1 & - & 4 & 2 \\
\hline Asociación de camélidos & - & - & 3 & 1 \\
\hline Camélidos y no figurativos & - & 3 & 4 & - \\
\hline $\begin{array}{l}\text { Camélidos, cabeza de camélido, cánido y no } \\
\text { figurativo }\end{array}$ & - & - & 1 & - \\
\hline $\begin{array}{l}\text { Camélidos, camélidos unidos por el cuello con } \\
\text { soga, équido y no figurativos }\end{array}$ & - & - & 1 & - \\
\hline $\begin{array}{l}\text { Camélidos, felinos, rheido, cuero, pisada de ave, } \\
\text { zoo indeterminado y no figurativos }\end{array}$ & - & - & - & 1 \\
\hline No figurativos & 4 & 2 & 31 & 4 \\
\hline
\end{tabular}

Tabla 3. Riqueza, especificidad y afinidad temática entre áreas.

Table 3. Thematic richness, specificity and affinity of different areas.

\begin{tabular}{|l|c|c|c|c|}
\hline & $\begin{array}{c}\text { Totora Huasi / } \\
\text { Agua de Ramón }\end{array}$ & Ampiza & Lomas Negras & $\begin{array}{c}\text { Virgen } \\
\text { de la Peña }\end{array}$ \\
\hline \% del total de temas (*) & $42,1 \%$ & $31,6 \%$ & $68,4 \%$ & $26,3 \%$ \\
\hline \% de temas propios (**) & $15,8 \%$ & $10,5 \%$ & $26,3 \%$ & $5,3 \%$ \\
\hline Totora Huasi / Agua de Ramón & - & $25 \%$ & $62,5 \%$ & $25 \%$ \\
\hline Ampiza & $33,3 \%$ & - & $66,7 \%$ & $33,3 \%$ \\
\hline Lomas Negras & $38,5 \%$ & $30,8 \%$ & - & $30,8 \%$ \\
\hline Virgen de la Peña (***) & $40 \%$ & $40 \%$ & $80 \%$ & - \\
\hline
\end{tabular}

* indicador de riqueza temática; ** indicador de especificidad; *** últimas cuatro filas, afinidad temática entre áreas. 
fila se considera la riqueza temática por área (porcentaje del total de temas) y en la segunda su grado de particularidad, esto es, el porcentaje de temas propios, que no se repiten en las otras áreas consideradas (en rigor, no más allá de cada sitio particular). Dejando de lado las diferencias entre sí (que existen y son importantes) las áreas TH/AR, AM y VP incluyen un menor porcentaje del total de temas y poseen un menor porcentaje de temas propios que LN, que muestra el mayor nivel de riqueza y especificidad temática. ${ }^{4}$

En las últimas cuatro filas se considera el grado de afinidad temática en términos de relaciones bilaterales entre áreas (expresado en porcentaje de temas compartidos; ver Martel \& Aschero 2007). Esta es una medida de interés ya que permitiría estimar, por ejemplo, hasta qué punto un sujeto habituado a recorrer un determinado territorio encontraría familiaridad o distancia al observar los temas del arte rupestre en otro. Se observan algunas tendencias significativas. Las áreas TH/AR, AM y VP muestran una menor afinidad en sus diferentes relaciones bilaterales, que la que sostiene cada una de ellas con LN. Es decir, que sujetos hipotéticos habituados a recorrer y significar esos entornos particulares encontrarían pocas similitudes en el arte rupestre de cualquier otro excepto en LN, donde todos hallarían mayores referencias conocidas. Por su parte, un sujeto habituado específicamente al entorno de LN, trasladado a cualquiera de los restantes, observaría más particularidades locales que temas compartidos o familiares a su experiencia (no obstante existentes; Gráfico 1).

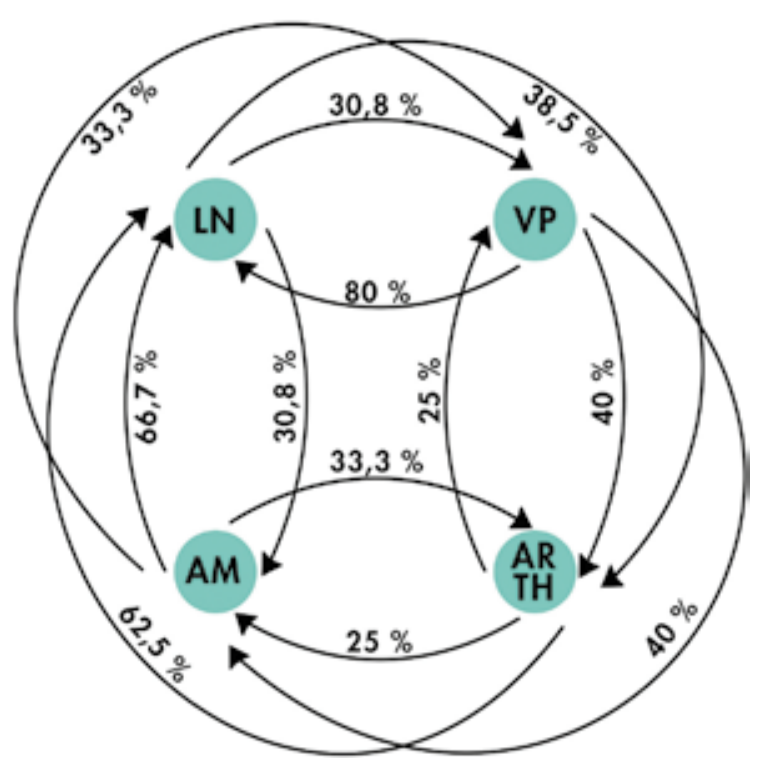

Gráfico 1. Afinidad temática entre áreas. Graph 1. Thematic affinity among areas.

\section{SELECCIÓN DE SOPORTES Y CONDICIONES DE VISIBILIDAD}

La localización del soporte y en particular de los paneles con arte rupestre es el resultado de elecciones que tuvieron consecuencias directas sobre sus posibilidades de visualización y el modo de interacción con el paisaje. Estas decisiones pueden denotar la intención de hacer accesible a otros, o no, el conjunto de prácticas (rituales, culinarias, etc.) asociado a la ejecución y la interacción con las imágenes (Criado Boado 1999; Piazzini 2006). La Tabla 4 resume la información sobre los tipos de soporte utilizados y las condiciones de visibilidad. En GN (áreas TH/AR y AM), con predominio de las rocas metamórficas, se seleccionaron paredones y bloques a cielo abierto $(n=20)$ y minoritariamente aleros $(n=2)$. Son comunes los soportes y los paneles altamente visibles $(59,1 \%)$ frente a aquellos con visibilidad media $(31,8 \%)$ o baja (9,1\%; fig. 14). ${ }^{5}$

En Serrezuela (áreas LN y VP), un paisaje caracterizado por las geoformas graníticas, se utilizaron soportes más variados. Sin embargo, se observan contrastes significativos en los criterios de selección en cada área, con consecuencias directas sobre la visibilidad del arte rupestre. En LN se eligieron paredones y bloques a cielo abierto, aleros y pequeñas oquedades. En un caso puntual (sitio El Cajón) se grabaron más de doscientos hoyuelos en el interior de un depósito de agua, en puntos de baja visibilidad. Más allá de este ejemplo, y de otros dos localizados en el sitio Cajones del Igno 1 que repiten la condición de baja visibilidad, predominan en el área los paneles con visibilidad media (46,6\%) y alta (31,0\%). Por el contrario, en VP se seleccionaron mayoritariamente aleros y tafones que impiden la observación de las figuras si no es a corta distancia, ingresando al interior de los refugios, y por pocas personas a la vez (fig. 15). En este aspecto, el arte rupestre de VP se aleja de los patrones de alta visibilidad, o de visibilidad no restringida, observados en las restantes áreas investigadas y se aproxima a la situación de GS, donde predominan los emplazamientos en el interior de abrigos rocosos con acceso visual restringido (Recalde 2009; Recalde \& Pastor 2012).

\section{ASOCIACIÓN CON RECURSOS NATURALES Y OTROS MATERIALES ARQUEOLOGICOS}

Los principales recursos asociados a los paneles con arte rupestre son de tipo hídrico y forestal (frutos comestibles de árboles, arbustos y cactáceas), además de la 
Tabla 4. Elección de soportes y condiciones de visibilidad. Table 4. Choice of support and visibility conditions.

\begin{tabular}{|c|c|c|c|c|}
\hline Tipo de soporte / Visibilidad & $\begin{array}{c}\text { Totora Huasi / } \\
\text { A. de Ramón }\end{array}$ & Ampiza & $\begin{array}{c}\text { Lomas Negras } \\
\text { de la Peña }\end{array}$ \\
\hline Paredón o bloque a cielo abierto / Alta & 9 & 4 & - \\
\hline Paredón o bloque a cielo abierto / Media & 3 & 2 & - \\
\hline Paredón o bloque a cielo abierto / Baja & - & 2 & - \\
\hline Paredón en pozo de agua / Media & - & - & - \\
\hline Paredón en pozo de agua / Baja & - & - & 1 \\
\hline Alero / Alta & - & - & - \\
\hline Alero / Media & - & - & - \\
\hline Alero / Baja & 1 & 1 & - \\
\hline Oquedad / Alta & - & - & 2 & - \\
\hline Oquedad / Media & - & - & 10 \\
\hline Oquedad / Baja & - & - & - \\
\hline Tafón / Baja & - & - & - \\
\hline
\end{tabular}
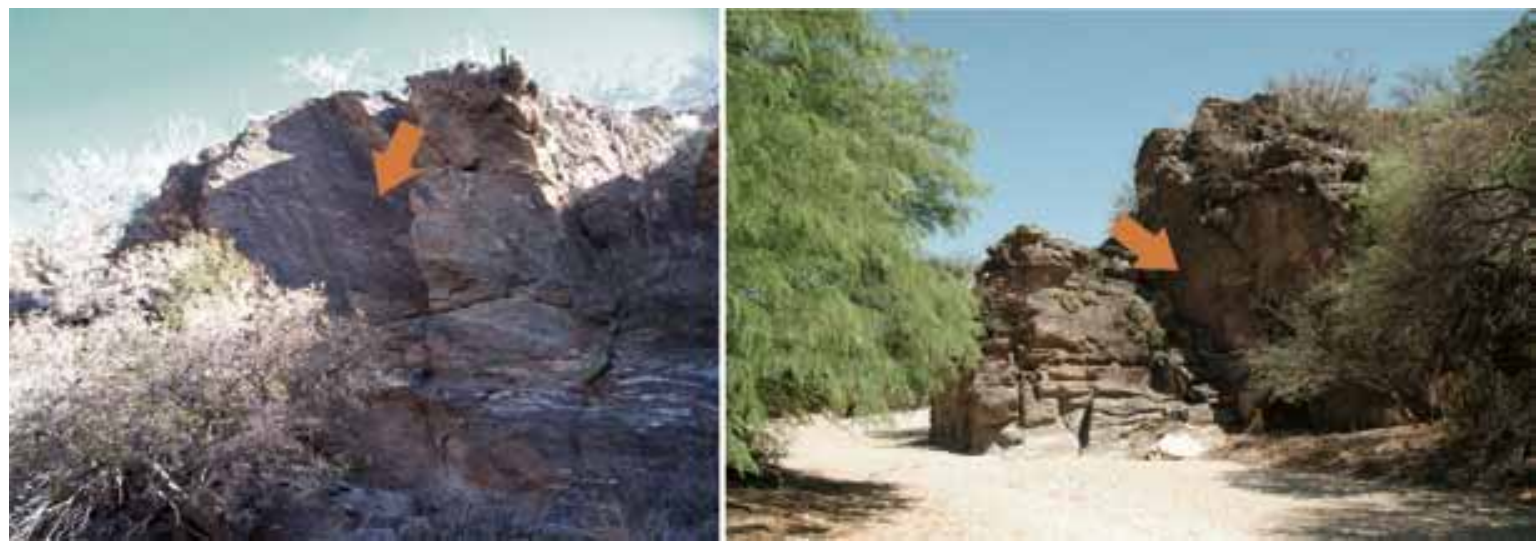

Figura 14. Elección de soportes altamente visibles en AM. Sitios Rodeo de Auti 8 (izquierda) y Río Guasapampa 2 (derecha). Figure 14. Selection of highly visible supports at AM. Rodeo de Auti 8 (left) and Río Guasapampa 2 (right) sites.

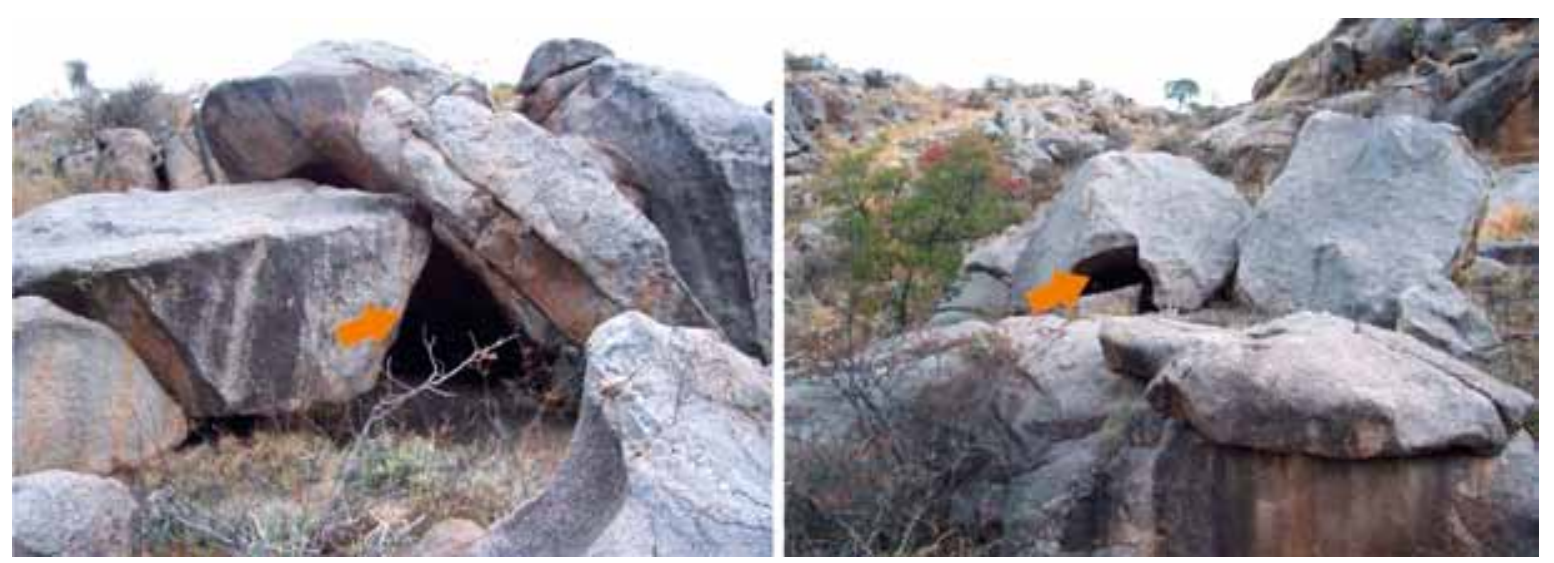

Figura 15. Elección de soportes de baja visibilidad en el interior de abrigos rocosos. Sitios Pozo de la Tosca 1 (izquierda) y Pozo de la Tosca 2 (derecha), área VP.

Figure 15. Selection of low visibility supports inside rock shelters. Pozo de la Tosca 1 (left) and Pozo de la Tosca 2 (right) sites, VP area. 
protección o el reparo que, en determinadas ocasiones, ofrecieron algunos abrigos rocosos. En las dos áreas prospectadas en GN (TH/AR y AM) todos los sitios con grabados se relacionan con la quebrada principal por donde discurre el río Guasapampa (normalmente seco), o con los fondos de quebradas laterales y tributarias. En general se ocuparon puntos específicos donde se almacena el agua de lluvia ("pozos" y "cajones"). Este panorama se extiende a las vertientes del cordón de Serrezuela, donde también se aprovecharon algunos aleros y tafones cercanos a las aguadas.

Los procesos erosivos que provocan la pérdida de los suelos, generalizados en la zona, atentaron contra la conservación de depósitos estratificados en casi todos los sitios y, en especial, en aquellos con arte rupestre, muchas veces relacionados con cauces que experimentan desbordes tras las lluvias torrenciales. En algunos casos (p. ej., los grabados en paredones en las márgenes del río) no existen indicios de la realización de otras actividades, más allá de la ejecución de las figuras. En otros sitios existen indicadores de prácticas asociadas de procesamiento y consumo de alimentos. Se han observado restos diversos en superficie (fragmentos cerámicos, instrumentos líticos, desechos de talla) relacionados con dichas tareas, aunque las dispersiones son pequeñas y nunca alcanzan altas densidades. La presencia de restos cerámicos y los diseños de las puntas de proyectil permiten asignar estas ocupaciones a momentos posteriores a $c a .1500$ años $\mathrm{AP}^{6}$

Un tipo de material ubicuo en el área (como en general en todas las sierras de Córdoba) comprende a los útiles de molienda pasivos (morteros y molinos) confeccionados en soportes rocosos fijos. Como el arte rupestre, estos útiles no son impactados por los procesos erosivos que afectan al suelo, pero presentan similares inconvenientes para su datación absoluta. Considerando en conjunto al sector central de las sierras de Córdoba, se conocen dataciones directas para contextos estratificados próximos a bloques rocosos con útiles de molienda (Pastor 2007b; Rivero et al. 2007-2008; Medina 2008; Recalde 2009). Estos fechados se concentran en el Holoceno Tardío, particularmente en el período 1500350 años AP, en tanto que los contextos más antiguos podrían remontarse hasta fines del Holoceno Medio ( $c a$. 4000/3000 años AP). De este modo, se define para la mayoría de los sitios (que son exclusivamente superficiales) un marco cronológico de grano grueso, comprendiendo buena parte del Holoceno Tardío. Aunque no se puede acceder a fechas absolutas ni a procesos o eventos de corta duración, el análisis de la distribución, la densidad y las características de los instrumentos nos informa positivamente sobre tendencias de largo plazo en el modo de ocupación del paisaje. Hemos potenciado el registro y el análisis de esta materialidad en un contexto donde escasean o faltan los depósitos estratificados, con las consecuentes limitaciones informativas (solo comentaremos aquí algunos resultados generales de este trabajo). El mismo ha permitido, específicamente, una aproximación a: 1) los criterios de elección de los lugares donde se desarrollaron las prácticas de molienda y, con toda probabilidad, otras relacionadas con la preparación y el consumo de alimentos; 2) el grado de articulación espacial con los paneles con representaciones rupestres; 3) la intensidad de la ocupación del paisaje a diferentes escalas, y 4) el tamaño probable del grupo de personas que habitualmente interactuaba en cada sitio o localidad.

En GN (áreas TH/AR y AM) los sitios con útiles de molienda se localizan en quebradas de diferente jerarquía y en relación con aguadas, como ocurre con el arte rupestre. En pocos casos se aprovechó la protección de abrigos rocosos. Sin embargo, a pesar de ocupar las mismas unidades del paisaje, la localización puntual de los sitios de molienda no tiende a coincidir con los lugares donde se ejecutaron los grabados.

En LN y VP, sobre ambas vertientes del cordón de Serrezuela, se ocuparon afloramientos y bloques cercanos a pozos de agua, aleros y tafones. La articulación con los paneles con arte ocurre de manera diferente en cada área. En LN los paneles se asocian directamente con los útiles de molienda (fig. 6), mientras que en VP el vínculo es indirecto, ya que se localizan a cierta distancia sin que sea posible, desde la posición de los operadores, la observación de los motivos. ${ }^{7}$ En ambos casos se aprecian diferencias con GN, donde la asociación espacial entre ambas esferas de actividad fue inexistente en la mayoría de los casos (solo en cuatro sitios de GN, sobre un total de 36, coincide la localización de útiles de molienda y motivos rupestres).

En cuanto a las estimaciones sobre la intensidad de la ocupación, debemos comentar dos resultados significativos (Gráfico 2). Tres de las cuatro áreas investigadas (AM, LN y VP) presentan una densidad casi idéntica de útiles de molienda por unidad de superficie. Frente a esto, la densidad registrada en TH/AR es muy baja. Estas apreciaciones pueden ser ampliadas considerando, adicionalmente, la densidad de motivos rupestres. Así, se observa que las tres áreas que presentan una densidad similar de útiles de molienda, muestran diferencias notables en cuanto a los motivos rupestres (la mayor densidad se registra en VP, seguida por LN y finalmente AM). Pero aquí nuevamente, y por una vía independiente, se detectan indicadores de una intensidad de ocupación muy baja para TH/AR, que es el área con menor densidad de imágenes rupestres.

Con respecto al tamaño de los grupos habitualmente integrados en cada sitio, también se efectuaron 


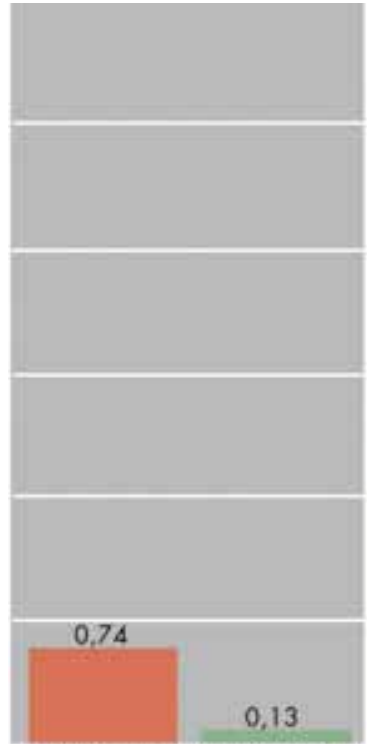

TOTORA HUASI / A.DE RAMÓN

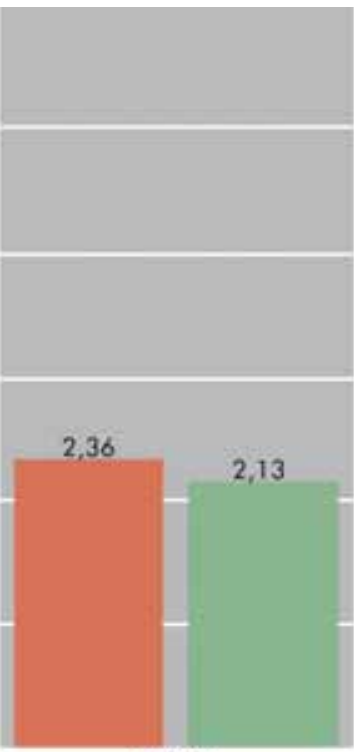

AMPIZA

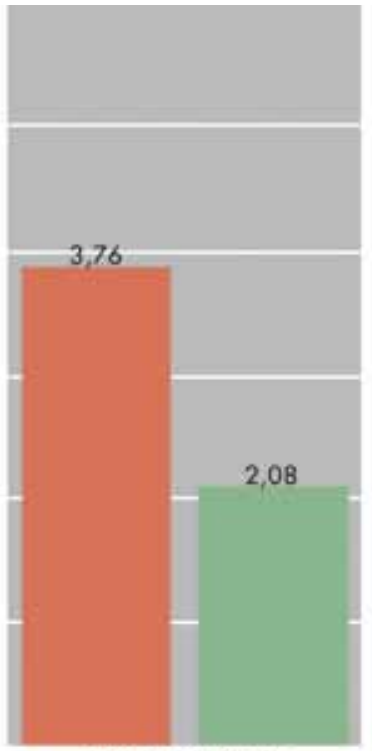

LOMAS NEGRAS

Útiles de molienda por $\mathrm{km}^{2}$

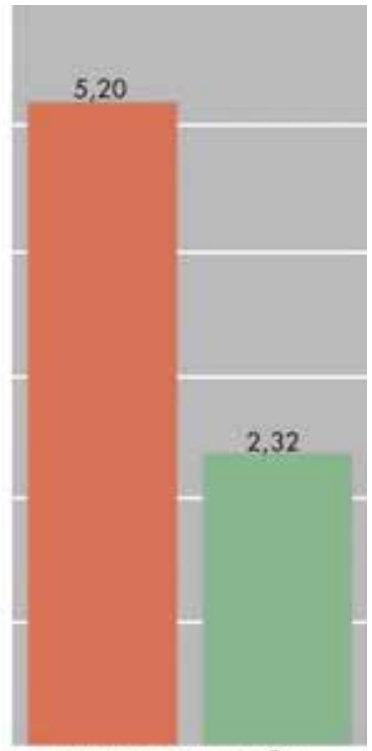

VIRGEN DE LA PEÑA

Motivos rupestres por $\mathrm{km}^{2}$

Gráfico 2. Densidad de motivos rupestres y útiles de molienda fijos en las áreas consideradas.

Graph 2. Density of rock art motifs and stationary grinding tools in the areas considered.

observaciones de interés por sus consecuencias para la identificación de diferentes escalas de interacción social. En TH/AR los sitios son escasos y pequeños. El número posible de personas operando simultáneamente los equipos de molienda de un mismo tipo (NOP-T) no supera las cuatro. ${ }^{8}$ De un modo general, los sitios son atribuidos a una escala doméstica de interacción, o a lo sumo, implicando la participación de pocas unidades familiares. El panorama es similar en AM y VP, aunque en la primera se detectaron sitios con valores de NOP-T de 8 y 9 , en tanto que en la segunda se registró un único sitio con un NOP-T de 12. Estos lugares puntuales sugieren la integración de colectivos sociales más inclusivos que, seguramente, excedían la simple escala doméstica. Estas tendencias son más marcadas en LN, donde sobresalen tres sitios que sugieren la conformación de grupos de un tamaño considerable, referidos a una escala comunitaria. Los mismos se ubican en los pozos de agua más importantes: Pozo de la Sacha Cabra $($ NOP-T $=18)$, Cajones del Igno $1($ NOP-T $=19)$ y El Cajón 1 (NOP-T = 38).

\section{DISCUSIÓN Y COMENTARIOS FINALES}

El problema fundamental que orienta la investigación es la participación del arte rupestre en la construcción del paisaje, la estructuración de lugares y territorios y la delimitación y la reproducción de las relaciones sociales. En esta perspectiva de análisis, interesa tanto aquello que se representa (motivos, cánones de diseño, temas), como el contexto más amplio que integra a las imágenes (elección de soportes, visibilidad, posibilidades de acceso a los recursos y otras prácticas asociadas).

El estudio se enfoca en cuatro áreas del cordón occidental de las sierras de Córdoba (Argentina) y comprende un período que se extendió por aproximadamente un milenio antes de la invasión europea en el siglo XVI, para continuar luego por unos pocos años o décadas. Se trata de un paisaje árido, definido por la escasez hídrica y por el valor de sus recursos forestales, en particular las especies dotadas de frutos comestibles. Los grupos indígenas de este período habían consolidado oasis agrícolas en los valles más fértiles que se extienden hacia el oriente (20-50 km, aproximadamente), donde tenían asentados sitios habitacionales y parcelas de cultivo (Pastor \& Berberián 2007; Medina 2008; Pastor et al. 2012). Los datos disponibles dan cuenta de una alta movilidad residencial y de la ocupación efectiva de los diferentes microambientes serranos, en relación con procesos de fisión o dispersión estacional. En este marco, la ocupación temporal de los cordones occidentales (Pocho, Guasapampa y Serrezuela) durante la estación estival, con mayor disponibilidad hídrica $\mathrm{y}$ de frutos silvestres, es un mecanismo indicado por diferentes líneas de evidencia (Recalde 2009; Pastor \& 
Recalde 2009; Pastor 2010). Una huella arqueológica muy débil para momentos anteriores a $c a$. 1500 años AP nos presenta este espacio como un paisaje poco frecuentado, cuya ocupación efectiva fue posterior y coincidente con transformaciones profundas en el modo de vida indígena con la adopción de prácticas agrícolas y cambios tecnológicos; en los patrones de asentamiento y movilidad; en la intensidad de explotación de los recursos, de las interacciones extrarregionales y en la organización sociopolítica (Berberián 1999; Laguens 1999; Bixio et al. 2010; Pastor et al. 2012).

Los resultados de dos trabajos previos (Recalde 2009; Recalde \& Pastor 2012) definen un punto de partida para encuadrar el análisis y la interpretación que se presentan en esta oportunidad. En primer término, en el caso de la concentración de sitios con arte rupestre de GS, casi siempre se seleccionaron soportes de visibilidad media o baja, en el interior de aleros y tafones (las representaciones solo pueden ser observadas a corta distancia, ingresando al interior de los refugios). Se registró un uso mayoritario de las pinturas frente a los grabados, así como de motivos zoomorfos con un amplio predominio de los camélidos, que resultan fundamentales en la constitución de las asociaciones temáticas (con menos frecuencia se representaron cérvidos, cánidos, rheidos, équidos, teíidos, felinos y suidos). También se documentaron antropomorfos (en su mayoría del canon A), motivos fitomorfos como cactáceas y no figurativos. Los materiales recuperados en depósitos estratificados informan sobre las actividades de procesamiento y consumo de alimentos y acerca de las repetidas reocupaciones durante un período extendido entre ca. 1400 y 400 años AP (en el mismo sentido del retorno reiterado apuntan las diferencias tonales y en ocasiones, la superposición de motivos rupestres).

Se ha planteado que, más allá de su variabilidad, el arte rupestre de GS fue un medio importante para la significación de lugares puntuales, esto es, pequeños refugios rocosos utilizados en forma transitoria pero repetida por unidades sociales mínimas (p. ej., familias nucleares). La existencia de motivos, cánones y temas de amplia circulación, junto a otros restringidos a localidades o sitios puntuales, fue relacionada con la reproducción de sentidos de identidad y pertenencia entre estos grupos mínimos, apelando a temas y significados altamente generalizados, así como a otros menos compartidos. Teniendo en cuenta la frecuente invisibilidad de las imágenes desde el exterior, se planteó que estas construcciones fueron limitadas al seno de cada grupo familiar y, de algún modo, negadas u omitidas en la interacción con otras personas. En el caso de GS, el conjunto de datos disponibles (arte rupestre, útiles de molienda, contextos estratificados) sugiere una intensa ocupación y significación de este paisaje, presumiblemente compartido por los diferentes grupos que retornaban al mismo en forma periódica. Esto es, un espacio sin límites o restricciones para la circulación y el acceso a los recursos (Recalde 2009).

Evidentemente estos planteamientos no pueden ser sostenidos en los mismos términos en GN, y este fue el problema abordado en el segundo trabajo (Recalde \& Pastor 2012), en el que se pusieron de relieve los contrastes del arte rupestre de ambas secciones del valle. En GN se presentan grabados en soportes altamente visibles, no se utilizaron abrigos rocosos como refugios, los camélidos tienen una menor frecuencia y, frente a ellos, los motivos no figurativos alcanzan una mayor representación. Además, destacan los antropomorfos con aditamentos que, por su predominio en el total de representaciones o por el destaque de algunas figuras particulares, estructuraron una cierta cantidad de temas. Contemplando estas diferencias, se argumentó que el arte de GN participó de un modo distinto en la construcción del paisaje. No se trataría, como en GS, de la significación de lugares puntuales por grupos mínimos de pertenencia, de una práctica limitada a la interacción entre pocas personas e invisibilizada hacia el exterior, en un paisaje intensamente apropiado y compartido. Por el contrario, estaría ligado a la demarcación de territorios y sus sitios más valiosos. La alta visibilidad y los temas definidos por los antropomorfos con aditamentos (posibles referencias jerárquicas o de poder), fueron interpretados como testimonios de la imposición de límites a la circulación y el acceso a los hitos clave en este ambiente semidesértico (las aguadas estacionales), cuyo aprovechamiento habría sido restringido o controlado por unos grupos frente a otros.

En la Tabla 5 se sintetizan, mediante palabras y conceptos clave, las principales observaciones efectuadas en cada una de las áreas incluidas en este trabajo. Un resultado importante y que merece ser destacado es que, a pesar de su reducido tamaño (unos 60 por 20 $\mathrm{km}, 1200 \mathrm{~km}^{2}$, aproximadamente), el área de estudio (incluyendo GS) muestra diferencias significativas en sus modos de ocupación y significación, con acentuadas variaciones locales. El conjunto de datos indica una utilización discontinua de los sitios, con eventos sucesivos de abandono y reutilización. Solo la ocupación y la explotación del paisaje en la temporada estival, cuando coincidían la mayor disponibilidad hídrica y los frutos silvestres, serían aspectos comunes a todos sus sectores.

En otros aspectos sobresalen los contrastes antes que las similitudes entre áreas. Por ejemplo la intensidad de la ocupación, estimada por la densidad de útiles de 
Tabla 5. Principales características de las áreas.

Table 5. Main features of the areas.

\begin{tabular}{|c|c|c|c|c|}
\hline & TH/AR & AM & $\mathrm{LN}$ & VP \\
\hline $\begin{array}{c}\text { Intensidad de la } \\
\text { ocupación }\end{array}$ & $\begin{array}{l}\text { Mínima, territorio } \\
\text { poco ocupado. }\end{array}$ & Media. & Alta. & Media / alta. \\
\hline $\begin{array}{c}\text { Escalas de interacción } \\
\text { social }\end{array}$ & $\begin{array}{c}\text { Unidades sociales } \\
\text { mínimas. }\end{array}$ & $\begin{array}{l}\text { Grupos mayores a la } \\
\text { unidad mínima en } \\
\text { sitios puntuales. }\end{array}$ & $\begin{array}{c}\text { Escala comunitaria } \\
\text { en pozos de agua } \\
\text { principales. }\end{array}$ & $\begin{array}{c}\text { Escala comunitaria en } \\
\text { un sitio puntual (pozo } \\
\text { principal). }\end{array}$ \\
\hline $\begin{array}{l}\text { Emplazamiento de } \\
\text { los paneles con arte } \\
\text { rupestre }\end{array}$ & $\begin{array}{l}\text { En relación con } \\
\text { aguadas, sin coincidir } \\
\text { con los lugares de } \\
\text { procesamiento y } \\
\text { consumo. }\end{array}$ & $\begin{array}{l}\text { En relación con } \\
\text { aguadas, sin coincidir } \\
\text { con los lugares de } \\
\text { procesamiento y } \\
\text { consumo. }\end{array}$ & $\begin{array}{c}\text { Pozos de agua } \\
\text { y aleros, en } \\
\text { articulación directa } \\
\text { con procesamiento y } \\
\text { consumo. }\end{array}$ & $\begin{array}{l}\text { Tafones y aleros } \\
\text { cercanos a pozos de } \\
\text { agua y a sitios de } \\
\text { molienda. }\end{array}$ \\
\hline Visibilidad / función & $\begin{array}{l}\text { Alta. Demarcación } \\
\text { de territorios e hitos } \\
\text { importantes en el } \\
\text { paisaje como aguadas } \\
\text { y algarrobales. } \\
\text { Imposición de } \\
\text { restricciones a la } \\
\text { circulación y el acceso } \\
\text { a los recursos. }\end{array}$ & $\begin{array}{l}\text { Alta. Demarcación } \\
\text { de territorios e hitos } \\
\text { importantes en el } \\
\text { paisaje como aguadas } \\
\text { y algarrobales. } \\
\text { Imposición de } \\
\text { restricciones a la } \\
\text { circulación y el acceso } \\
\text { a los recursos. }\end{array}$ & $\begin{array}{c}\text { Predomina alta. } \\
\text { Demarcación de } \\
\text { hitos importantes en } \\
\text { el paisaje (pozos) y } \\
\text { geoformas destacadas } \\
\text { o con buen control } \\
\text { visual (conteniendo } \\
\text { aleros). Imposición } \\
\text { de restricciones a la } \\
\text { circulación y acceso a } \\
\text { los recursos. }\end{array}$ & $\begin{array}{l}\text { Baja. Significación } \\
\text { de refugios de uso } \\
\text { reiterado, como } \\
\text { práctica "hacia } \\
\text { adentro" entre } \\
\text { grupos mínimos. } \\
\text { Paisaje compartido, } \\
\text { sin restricciones a la } \\
\text { circulación y acceso a } \\
\text { los recursos. }\end{array}$ \\
\hline Motivos / temas & $\begin{array}{l}\text { Marcada especificidad } \\
\text { local. Frecuencia } \\
\text { mínima de camélidos. }\end{array}$ & $\begin{array}{l}\text { Elementos únicos } \\
\text { o poco frecuentes } \\
\text { junto a otros de } \\
\text { amplia circulación } \\
\text { (camélidos A1 y A2, } \\
\text { antropomorfos A). }\end{array}$ & $\begin{array}{l}\text { Mayor cantidad de } \\
\text { temas y de temas } \\
\text { propios. En cuanto a } \\
\text { afinidad temática, fue } \\
\text { la mayor referencia } \\
\text { para las restantes } \\
\text { áreas. }\end{array}$ & $\begin{array}{l}\text { Marcada especificidad } \\
\text { local, aunque se } \\
\text { presentan elementos } \\
\text { de mayor circulación } \\
\text { (camélidos A y C, } \\
\text { antropomorfos A). }\end{array}$ \\
\hline $\begin{array}{l}\text { Antropomorfos A3, B } \\
\text { y C (y temas que los } \\
\text { incorporan) }\end{array}$ & $\begin{array}{c}\text { Refuerzan la oposición } \\
\text { con GS y denotan } \\
\text { continuidad con AM } \\
\text { y LN. }\end{array}$ & $\begin{array}{l}\text { Continuidad con las } \\
\text { áreas contiguas (LN } \\
\text { y TH/AR) y distancia } \\
\text { con GS y con VP. }\end{array}$ & $\begin{array}{l}\text { Continuidad con GN y } \\
\text { distancia con GS y VP } \\
\text { (área contigua). }\end{array}$ & No se presentan. \\
\hline No figurativos & $\begin{array}{l}\text { Máxima } \\
\text { representación, con un } \\
66 \% \text { de motivos. }\end{array}$ & $\begin{array}{c}\text { Menor representación, } \\
\text { con un } 39 \% \text { de los } \\
\text { motivos. }\end{array}$ & $\begin{array}{c}\text { Menor representación, } \\
\text { con un } 44 \% \text { de los } \\
\text { motivos. }\end{array}$ & $\begin{array}{l}\text { Máxima } \\
\text { representación, con un } \\
66 \% \text { de motivos. }\end{array}$ \\
\hline
\end{tabular}

molienda y de motivos rupestres, muestra diferencias significativas, con áreas intensamente ocupadas (LN y VP), otras con valores medios (AM) y finalmente el caso de $\mathrm{TH} / \mathrm{AR}$, que se presenta como un paisaje poco habitado.

Los sitios donde se procesaron y consumieron alimentos muestran relaciones variables con las aguadas, abrigos rocosos y paneles con arte rupestre (desde una articulación estrecha hasta la ausencia de vinculaciones directas o indirectas). También se observan diferencias en las probables escalas de interacción social. En TH/AR solo habrían interactuado unidades sociales pequeñas y muy dispersas. Este panorama general se extendería a AM y VP, solo que en algunos lugares puntuales, en ocasiones, se habrían conformado grupos de mayor tamaño. En tanto que en LN, en los pozos de agua principales, solían integrarse colectivos sociales aun mayores, referidos a una escala comunitaria de participación (Pastor 2010).

En este marco la variabilidad del arte rupestre, tanto a nivel de lo representado como en los contextos de producción, se constituye en un indicador firme de su participación diferencial en los procesos de construcción del paisaje. La modalidad distintiva de GS no se repite en las restantes áreas, no obstante sus principales elementos son reconocidos en VP. En ambos casos, el arte se asocia a refugios ocupados en forma repetida por grupos pequeños que desarrollaron diversas actividades cotidianas además de la ejecución de las imágenes. Tales acciones permanecían invisibles desde el exterior, donde los ocupantes de los abrigos circulaban, recolectaban frutos 
silvestres y realizaban algunas etapas de su procesamiento en morteros. Esto último, muchas veces, implicando la interacción con otras personas posiblemente cercanas (p. ej., por vínculos de parentesco o vecindad), pero ajenas a la unidad social mínima.

De este modo, el planteamiento general de Recalde (2009) para GS puede ser extendido al área VP, esto es, que el arte rupestre tuvo una participación activa en la significación de lugares puntuales y en la construcción de sentidos (p. ej., de identidad, de pertenencia) entre grupos mínimos, en un paisaje intensamente recorrido y explotado, pero a la vez compartido con otras unidades sociales semejantes. Pero es importante advertir que también se presentan particularidades y diferencias notables. Por ejemplo, la densidad de refugios utilizados y de motivos rupestres es inmensamente superior en GS, respecto a VP.

Por otra parte, la definición de una modalidad estilística propia para GN (Recalde \& Pastor 2012) se basa en la ponderación de los elementos ampliamente compartidos entre TH/AR y AM. A partir de los datos expuestos en esta oportunidad, los contrastes entre ambas áreas han quedado igualmente manifiestos. AM fue recorrida y explotada con una intensidad similar a otros sectores, en tanto que TH/AR muestra una intensidad de ocupación mínima. También se aprecian diferencias en las imágenes representadas, no menos significativas que las semejanzas. Los camélidos y los temas conformados a partir de estos, en el caso de AM, si bien ocurren con menos frecuencia que en GS, alcanzan porcentajes importantes (más del 40\% del total). En TH/AR estos motivos son casi inexistentes, mientras que los no figurativos son dos veces más frecuentes. Estos aspectos acentúan las diferencias temáticas de TH/AR con el resto de las áreas, en particular con el sector contiguo de GS.

Aunque las escalas de interacción fueron semejantes en las dos secciones del valle (GN y GS), implicando una o pocas unidades familiares en cada sitio de molienda, es claro que el arte rupestre no participó del mismo modo en la reproducción de los vínculos entre personas y grupos, y de estos con el paisaje. En GN la elección de soportes visibles, los temas incluyendo antropomorfos A3, B y C (posibles referencias jerárquicas o de poder), su localización relacionada con aguadas y vías de tránsito, y su separación del resto de las actividades cotidianas, coloca a estas expresiones en las antípodas de lo registrado en GS, así como en VP. No se trataría de una práctica orientada hacia un "nosotros" íntimo y familiar, sino lo contrario, de una acción asimismo dirigida hacia "otros", transmitiendo un mensaje diferente vinculado a la demarcación territorial. La máxima oposición temática entre TH/AR (un entorno poco habitado) y GS (uno intensamente explotado) indicaría posibles impedimentos o "prohibiciones" para la penetración y la circulación de los códigos desplegados en esta última, y con ello, de las personas que los significaban.

La situación de LN difiere de las anteriores. Como ocurre en GS y VP, y a diferencia de GN, el arte rupestre y las actividades de procesamiento y consumo tendieron a asociarse en los mismos lugares. En otro aspecto, la elección de soportes de visibilidad no restringida establece similitudes con GN y contrastes con GS y VP. En LN el arte rupestre se relaciona con pozos de agua donde interactuaron grupos pequeños excepto en aquellos de mayor jerarquía, donde ocasionalmente se integraron grupos más inclusivos. En esto se aprecian diferencias con las áreas restantes (excepto un sitio puntual en VP). La pequeña concentración de paneles con arte rupestre de LN (con relación a la concentración principal de GS), junto a otras líneas de información arqueológica, presentan a esta área como un paisaje intensamente explotado y significado. Los variados motivos y temas ejecutados en posiciones con un amplio acceso visual y, en ocasiones, en lugares de importancia pública, pudieron transmitir mensajes para un "nosotros" extendido (más allá de las relaciones domésticas), así como eventualmente para "otros". En cualquier caso, apelando a motivos y temas comunes con GN, donde algunas imágenes habrían cumplido un rol activo en la demarcación territorial. El análisis de las asociaciones de motivos y cánones indicó que en LN se desplegó la mayor cantidad de temas y existieron más temas propios o exclusivos, que no circularon fuera del área. Los cálculos de afinidad temática la señalaron como la mayor referencia para los hipotéticos ocupantes de las áreas adyacentes, quienes compartían entre sí pocos elementos relacionados con la producción y, probablemente, la significación del arte rupestre.

Este conjunto de observaciones permite plantear una serie de hipótesis sobre las relaciones políticas y territoriales entre los grupos que ocuparon el área de estudio. El avance sobre las mismas requerirá profundizar la investigación sobre distintas líneas, tanto en la zona como en los oasis agrícolas desde donde provenían sus antiguos pobladores.

Probablemente, a lo largo del período considerado diferentes comunidades (entendidas como colectivos multifamiliares con cierto grado de centralización y agencia política) ocupaban estacionalmente -durante la temporada estival- ambas secciones del valle de Guasapampa (GS y GN) y ambas vertientes del cordón de Serrezuela (LN y VP). Algunas de estas comunidades, o sus segmentos constitutivos (linajes, familias), 
pudieron apropiarse en forma particular de determinados territorios, donde producían un arte rupestre que, más allá de los elementos compartidos, mostraba notables variaciones locales. Estas particularidades podrían indicar la importancia de la producción del arte en relación con la reproducción social de los grupos de base (p. ej., unidades familiares nucleares, familias extensas), como proceso inseparable de la apropiación y significación de determinados sectores e hitos del paisaje.

La pertenencia a una comunidad o formación política mayor se materializaba, entre otras instancias, en el curso de celebraciones grupales o festines, como las "juntas" y "borracheras" que describieron los españoles en el tiempo de la conquista (Pastor 2007b). Las mismas habrían tenido lugar en torno a las aguadas principales, especialmente en el área LN. Estos agrupamientos debieron comprometer a personas habituadas a recorrer específicamente ese territorio así como a otras que normalmente accedían, explotaban y significaban bajo sus propios términos, otras zonas adyacentes. Eventualmente, unos y otros pudieron integrar una misma formación política, o bien grupos afines relacionados por la negociación, en cualquier caso con un determinado acceso y control territorial.

El poder de estas formaciones políticas pudo ser suficiente como para subexplotar y a la vez restringir el acceso a un territorio rico y dilatado como el que cubre el área TH/AR. Los "otros" hacia quienes se dirigía el mensaje restrictivo que distingue al arte rupestre del área, pudieron ser los grupos que hacían una intensa explotación y significación del paisaje contiguo de GS, pero bajo parámetros totalmente disímiles. Adicionalmente, el piedemonte occidental de las sierras de Pocho y Serrezuela pudo constituir un límite del rango de acción para los grupos asentados en las sierras de Los Llanos (La Rioja), a unos 80 o $100 \mathrm{~km}$ hacia el oeste. La posibilidad de compartir e interactuar en dichos espacios ofreció distintas alternativas de cooperación, intercambios y conflictos, estos últimos manifiestos, probablemente, en la temática jerárquica y restrictiva de buena parte del arte rupestre de GN y LN. Estos temas y significados no fueron expresados en VP, un área más cercana a los oasis agrícolas del río Pichanas y quizás, fuera del límite de acción de los grupos del sur riojano y de aquellos que ocupaban el área GS.

Los derechos sobre recursos estratégicos como las aguadas de mayor capacidad fueron objeto de negociación y base para el establecimiento y reproducción de asimetrías y desigualdades entre grupos (por ejemplo a favor de "linajes principales"), pero también para la cohesión interna de las comunidades. Las fuentes documentales del tiempo de la conquista muestran que los vínculos jerárquicos entre autoridades étnicas eran reconocidos y reforzados en situaciones públicas como las "borracheras", ocasionalmente bajo circunstancias coyunturales, como en años de sequía, cuando grupos relativamente autónomos debían negociar el acceso a los pozos de agua principales (que se mantenían con agua) con sus titulares (Montes 2008).

Lo expuesto hasta aquí son ideas y expectativas justificadas por los datos recuperados y por el grado de avance de los análisis desarrollados sobre los mismos. Cada una de ellas podrá ser mejor definida o sustentada a medida que se continúen y profundicen las investigaciones. En dicha instancia será conveniente abordar, por ejemplo, el análisis de las características y la variabilidad entre los motivos no figurativos, la comparación con el arte rupestre de zonas cercanas (lamentablemente poco conocidas hasta el presente, como las sierras de Los Llanos de La Rioja), así como potenciar los esfuerzos para obtener dataciones absolutas y, eventualmente, lograr la diacronización de algunas de sus principales modalidades.

RECONOCIMIENTOS Esta investigación forma parte del proyecto "Condiciones de posibilidad de reproducción social en sociedades prehispánicas y coloniales tempranas de las sierras pampeanas (República Argentina)", bajo la dirección del Dr. Eduardo Berberián y con la financiación del ConiceT (PIP 112-200801-02678). Deseo expresar mi reconocimiento a los doctores Andrea Recalde y Matías Medina por sus útiles observaciones al manuscrito, y a los estudiantes Luis Tissera, Ignacio Fernández, Iván Díaz y Luciano Cabezas por su participación en los trabajos de campo. Las ideas expuestas en el artículo son de mi exclusiva responsabilidad.

\section{NOTAS}

\footnotetext{
${ }^{1}$ Según datos fidedignos en el pasado existieron más sitios en esta área, lamentablemente desaparecidos por la intensa explotación de las canteras de granito donde se ubican muchos de los aleros y tafones con arte rupestre. En la década de 1970 se llegaron a registrar hasta 60 sitios (Romero et al. 1973), hoy reducidos en su número casi a la mitad.

${ }^{2}$ Otros dos motivos de este sitio podrían corresponder a cueros abiertos, pero son menos claros y fueron clasificados como "no figurativos". En GS también se documentó un motivo que se interpreta como un cuero abierto (Recalde com. pers. 2010).

${ }^{3}$ Siguiendo a Aschero (1997) usamos "tema" como asociaciones espaciales de clases de motivos, que pueden ocurrir en uno o en más de un sitio. Sin embargo, no tomamos el criterio de recurrencia (su repetición en más de una oportunidad) en términos absolutos, pues en nuestro caso la variabilidad del repertorio iconográfico y de las asociaciones es muy marcada. De este modo, numerosas asociaciones coherentes de motivos, por su cercanía y tonalidad o grado de pátina, serían excluidas del análisis por ocurrir en una sola oportunidad, según lo conocido hasta el momento. Metodológicamente, creemos conveniente incluir estos casos que aportan una medida de la especificidad local para determinados sitios y las áreas que los contienen. Según los parámetros definidos por el autor citado, también se consideran algunos temas definidos por motivos con distinto grado de pátina, pero en situaciones de proximidad espacial y con continuidad en las clases de motivos agregados.
} 
${ }^{4}$ Probablemente esta observación es inseparable del hecho de que en LN se documentó el mayor número de paneles y motivos. Sin embargo, más que un obstáculo para las comparaciones a nivel cuantitativo, la distribución concentrada de sitios constituye un dato en sí mismo, que debe ser tenido en cuenta en el momento de integrar y discutir los resultados.

${ }^{5}$ Los paneles con alta visibilidad se distinguen por la inexistencia de restricciones para la observación de las imágenes, incluso en forma simultánea por numerosas personas. Las figuras pueden ser percibidas sin dificultades hasta cierta distancia (10 m o más), circunstancia favorecida por sus posiciones específicas (p. ej., elección de partes altas de los soportes) y/o por su tamaño. La visibilidad media comprende casos donde los motivos pueden ser vistos en el rango de 4-5 m hasta 8-10 $\mathrm{m}$, ya sea por limitantes estructurales de los soportes rocosos, por la elección de posiciones de baja altura, por el tamaño pequeño de las figuras, etc. La visibilidad baja incluye paneles cuyas representaciones solo pueden ser apreciadas a corta distancia (menos de $3 \mathrm{~m}$ ), por parte de pocos observadores simultáneos, casi siempre en el interior de abrigos rocosos.

${ }^{6}$ Esto concuerda con el panorama detectado en GS, donde se conservan contextos estratificados que han podido ser datados directamente, con un rango de fechados entre 1360 y 390 años AP (Recalde 2009). También coincide con los resultados preliminares de sondeos efectuados en el único abrigo rocoso que conserva sedimentos en el área VP, donde se obtuvieron materiales en baja densidad incluyendo un pequeño conjunto cerámico, desechos de talla en cuarzo, rocas silíceas e incluso dos lascas de vidrio. Estas últimas, así como las representaciones de équidos y jinetes, indican la continuidad de la ocupación de determinados sitios y sectores del paisaje en tiempos coloniales tempranos.

${ }^{7}$ Excepto en Pozo de la Tosca 2 (área VP), donde se registraron dos molinos en el interior del tafón. Sin embargo, los morteros utilizados en forma complementaria se encuentran fuera del refugio, en posiciones cercanas a cielo abierto, lo cual indica que otras etapas de la molienda ocurrían en el exterior, implicando probablemente la interacción con otras personas.

${ }^{8}$ La medida NOP-T, relativa al número potencial de usuarios simultáneos de los instrumentos de molienda, ha sido estimada según los criterios de Babot (2007) con modificaciones. El número de usuarios propuesto se refiere a aquellos que pudieron utilizar simultáneamente los útiles del grupo tipológico más representado en el sitio, en concreto aquellos que aún se encuentran en condiciones de uso por no haber sufrido roturas.

\section{REFERENCIAS}

Aschero, C., 1996. ¿Adónde van esos guanacos? En Arqueología. Solo Patagonia, J. Gómez Otero, Ed., pp. 153-162. Puerto Madryn: Centro Nacional Patagónico.

— 1997. De cómo interactúan emplazamientos, conjuntos y temas. En Actas del XI Congreso Nacional de Arqueología Argentina. Revista del Museo de Historia Natural de San Rafael XVI (1/4): 17-28, San Rafael, Mendoza.

— 2007. Íconos, buancas y complejidad en la Puna Argentina. En Producción y circulación prebispánicas de bienes en el sur andino, A. Nielsen, V. Seldes, M. Vázquez \& P. Mercolli, Comps., pp. 135-165. Córdoba: Editorial Brujas.

Вавот, M., 2007. Organización social de la práctica de molienda: casos actuales y prehispánicos del Noroeste Argentino. En Procesos sociales prebispánicos en el sur andino: la vivienda, la comunidad y el territorio, A. Nielsen, V. Seldes, M. Vázquez \& P. Mercolli, Comps., pp. 259-290. Córdoba: Editorial Brujas.

BERBERIÁN, E., 1999. Sierras centrales. En Nueva historia de la nación argentina, Academia Nacional de la Historia, Ed., tomo I, pp. 135-158. Buenos Aires: Editorial Planeta.
Bixio, B.; E. Berberián \& S. PAstor, 2010. Historia prehispánica de Córdoba. Córdoba: Editorial Brujas.

Consens, M., 1986. San Luis - el arte rupestre de sus sierras. San Luis: Fondo Editorial Sanluiseño.

Criado Boado, F., 1999. Del terreno al espacio: planteamientos y perspectivas para la arqueología del paisaje. CAPA 6: 1-63, Santiago de Compostela.

Falchi, M.; M. Podestá, D. Rolandi, A. Re \& M. Torres, 2011. Arte rupestre entre las sierras y los llanos riojanos: localidad arqueológica Palancho. Comechingonia 15: 39-63, Córdoba.

Gallardo, F., 2001. Arte rupestre y emplazamiento durante el Formativo Temprano en la cuenca del río Salado (desierto de Atacama, norte de Chile). Boletín del Museo Chileno de Arte Precolombino 8: 83-97.

Gardner, G., 1931. Rock-painting of north-west Córdoba. Oxford: Clarendon Press.

Laguens, A., 1999. Arqueología del contacto bispano-indigena. Un estudio de cambios y continuidades en las sierras centrales de Argentina. Oxford: BAR, International Series 801.

Martel, A. \& C. Aschero, 2007. Pastores en acción: imposición iconográfica vs. autonomía temática. En Producción y circulación prebispánica de bienes en el sur andino, A. Nielsen, V. Seldes, M. Vázquez \& P. Mercolli, Comps., pp. 329-349. Córdoba: Editorial Brujas.

Medina, M., 2008. Diversificación económica y uso del espacio en el tardío prehispánico del norte del valle de Punilla, pampa de Olaen y llanura noroccidental (Córdoba, Argentina). Trabajo para optar al título de Doctor, Facultad de Filosofía y Letras, Universidad de Buenos Aires.

Menghin, O., 1957. Estilos del arte rupestre de Patagonia. Acta Praebistorica I: 57-87, Buenos Aires.

Montes, A., 2008. Indigenas y conquistadores de Córdoba. Buenos Aires: Editorial Isquitipe.

PAstor, S., 2007a. Arqueología del valle de Salsacate y pampas de altura adyacentes (sierras centrales de Argentina). Una aproximación a los procesos sociales del período prehispánico tardío (900-1573 DC). Trabajo para optar al título de Doctor, Facultad de Ciencias Naturales y Museo, Universidad Nacional de La Plata.

— 2007b. "Juntas y cazaderos". Las actividades grupales y la reproducción de las sociedades prehispánicas de las sierras centrales de Argentina. En Procesos sociales prebispánicos en el sur andino: la vivienda, la comunidad y el territorio, A. Nielsen, V. Seldes, M. Vázquez \& P. Mercolli, Comps., pp. 361376. Córdoba: Editorial Brujas.

— 2010. Aproximación inicial a la arqueología del norte de la sierra de Guasapampa y cordón de Serrezuela (Córdoba, Argentina). Arqueología 16: 151-174, Buenos Aires.

— 2012. Arte rupestre, paisaje y tensión social: Un caso de estudio en Córdoba, Argentina. Revista Chilena de Antropología 26 [en prensa].

PAstor, S. \& E. Berberián, 2007. Arqueología del sector central de las sierras de Córdoba (Argentina). Hacia una definición de los procesos sociales del período prehispánico tardío (9001573 DC). Intersecciones en Antropología 8: 31-49, Olavarría.

Pastor, S. \& A. Recalde, 2009. Primeras perspectivas sobre la ocupación prehispánica del norte del valle de Guasapampa (Córdoba, Argentina). Anuario de Arqueología 1: 19-28, Rosario.

Pastor, S.; M. Medina, A. Recalde, L. López \& E. Berberián, 2012. Arqueología de la región montañosa central de Argentina. Avances en el conocimiento de la historia prehispánica tardía. Relaciones de la Sociedad Argentina de Antropología XXXVII (1): 89-112, Buenos Aires.

Piazzini, C., 2006. Arqueología, espacio y tiempo: Una mirada desde Latinoamérica. Arqueología Sudamericana 2 (1): 3-25, Cauca.

RAGGIO, M., 1979. La roca grabada de San Buenaventura (Córdoba). Miscelánea de Arte Rupestre de la República Argentina. Monografias de Arte Rupestre, Arte Americano 1, Barcelona.

RE, A; M. Podestá \& G. ROMERo, 2011. Ocupaciones humanas y grabados rupestres del norte de la sierra de Valle Fértil (Provincia de San Juan). Comechingonia 15: 65-92, Córdoba. 
RECALDE, A., 2006. Las representaciones rupestres y su relación con el paisaje. Aproximación a un análisis regional en el sector occidental de las sierras de Córdoba. Comechingonia 9: 77-90, Córdoba.

2009. Diferentes entre iguales: El papel del arte rupestre en la reafirmación de identidades en el sur del valle de Guasapampa (Córdoba, Argentina). Boletín del Museo Chileno de Arte Precolombino 14 (2): 39-56.

— 2012. Análisis de la construcción de las figuras equinas en el arte rupestre del valle de Guasapampa como evidencia de una apropiación simbólica del conquistador (Córdoba, Argentina). Chungara 44 (1): 69-79.

Recalde, A. \& S. PASTOR, 2011. Variabilidad y dispersión de los diseños de camélidos en el occidente de Córdoba (Argentina). Circulación de información, reproducción social y construcciones territoriales prehispánicas. Comechingonia 15: 93-114, Córdoba. 2012. Contextos "públicos" y "privados" para la ejecución del arte rupestre en el valle de Guasapampa (Córdoba, Argentina). Latin American Antiquity 23 (3): 327-345, Washington, D. C.

Rivero, D.; V. Franco Salvi \& H. Paradela, 2007-2008. Funcionalidad de sitio y uso del espacio en las sierras de Córdoba durante el Holoceno (8000-3000 AP). Arqueología 14: 77-101, Buenos Aires.
Rocchietтi, A., 1991. Estilo y diferencia: Un ensayo en área espacial restringida. En El arte rupestre en la arqueología contemporánea M. Podestá, M. Hernández Llosas \& S. Renard de Coquet, Eds. pp. 25-30, Buenos Aires.

2009. El petroglifo del pinar del Cerro Negro: una aproximación al arte arqueológico. Revista de la Escuela de Antropología $\mathrm{XV}: 21-34$, Rosario.

Romero C.; E. Arguello De Dorsch \& M. UAnini, 1973. El arte rupestre de Córdoba. Proyecciones. Edición especial en homenaje al IV Centenario de la Fundación de Córdoba $\mathrm{N}^{\circ}$ 8, Córdoba.

Schobinger, J. \& C. Gradin, 1985. Cazadores de la Patagonia y agricultores andinos. Arte rupestre de la Argentina. Madrid: Ediciones Encuentro.

Troncoso, A., 2005. Un espacio, tres paisajes, tres sentidos: La configuración rupestre en Chile central. CAPA 33: 69-75, Santiago de Compostela.

URQUIZA, S., 2011. Arte rupestre de las sierras del norte de Córdoba, Argentina. Comechingonia 15: 115-137, Córdoba.

Vignati, M., 1939. El arte parietal indígena en Máscaras. Al norte de la provincia de Córdoba. Notas del Museo de La Plata, tomo IV, Antropología 14: 264-284. 
